\title{
Environmental Context Mediates Biodiversity-Ecosystem \\ Functioning Relationships in Coastal Soft-sediment Habitats
}

\section{Gammal, Johanna}

2019-01

Gammal , J , Järnström , M , Bernard , G , Norkko , J \& Norkko , A 2019 , ' Environmental Context Mediates Biodiversity-Ecosystem Functioning Relationships in Coastal Soft-sediment Habitats ' , Ecosystems , vol. 22 , no. 1, pp. 137-151 . https://doi.org/10.1007/s10021-018-0258-9

https://doi.org/10.1007/s10021-018-0258-9

cc_by

acceptedVersion

Downloaded from Helda, University of Helsinki institutional repository.

This is an electronic reprint of the original article.

This reprint may differ from the original in pagination and typographic detail.

Please cite the original version. 
This is the AUTHORS' ACCEPTED MANUSCRIPT, for the published article, please see: https://link.springer.com/article/10.1007/s10021-018-0258-9

Full citation:

Gammal J, Järnström M, Bernard G, Norkko J, Norkko A (2019) Environmental context mediates biodiversity-ecosystem functioning relationships in coastal soft-sediment habitats. Ecosystems 22:137-151

\section{Environmental context mediates biodiversity-ecosystem functioning relationships in coastal soft-sediment habitats}

Johanna Gammal $^{1 *}$, Marie Järnström², Guillaume Bernard ${ }^{1,3}$, Joanna Norkko ${ }^{1}$, Alf Norkko ${ }^{1,4}$

${ }^{1}$ Tvärminne Zoological Station, University of Helsinki, J.A. Palméns väg 260, 10900 Hangö, Finland

${ }^{2}$ Environmental and Marine Biology, Åbo Akademi University, Artillerigatan 6, 20520 Åbo, Finland

${ }^{3}$ CNRS, EPOC, UMR5805, F33400 Talence, France

${ }^{4}$ Baltic Sea Centre, Stockholm University, Stockholm, Sweden

${ }^{*}$ Corresponding author: johanna.gammal@ helsinki.fi, +358294128055

Author Contributions: JG, MJ, GB, JN, AN designed the study and performed the research; JG, MJ, GB conducted the laboratory analyses; JG analysed the data; JG wrote the first draft of the manuscript and all authors contributed substantially to revisions. 


\begin{abstract}
The ongoing loss of biodiversity and global environmental changes severely affect the structure of coastal ecosystems. Consequences, in terms of ecosystem functioning are, however, difficult to predict because the context dependency of the biodiversity-ecosystem function relationships within these heterogeneous seascapes is poorly understood. To assess the effects of biological and environmental factors in mediating ecosystem functioning (nutrient cycling) in different natural habitats, intact sediment cores were collected at 18 sites on a grain size gradient from coarse sand to silt, with varying organic matter content and vegetation. To assess ecosystem functioning, solute fluxes $\left(\mathrm{O}_{2}, \mathrm{NH}_{4}{ }^{+}, \mathrm{PO}_{4}{ }^{3-}, \mathrm{Si}\right)$ across the sediment-water interface were measured. The macrofaunal communities changed along the grain size gradient with higher abundance, biomass and number of species in coarser sediments and in habitats with more vegetation. Across the whole gradient, the macrofauna cumulatively accounted for $25 \%$ of the variability in the multivariate solute fluxes, whereas environmental variables cumulatively accounted for $20 \%$. Only the biomass and abundance of a few of the most dominant macrofauna species, not the number of species, appeared to contribute significantly to the nutrient recycling processes. Closer analyses of different sediment types (grouped into coarse, medium and fine sediment) showed that the macrofauna was an important predictor in all sediment types, but had the largest impact in fine and medium sediments. The results imply that even if the ecosystem functioning is similar in different sediment types, the underpinning mechanisms are different, which makes it challenging to generalize patterns of functioning across the heterogeneous shallow coastal zones.
\end{abstract}

Key words: biodiversity-ecosystem functioning; benthic macrofauna; sediment grain size; solute fluxes; environmental gradient; spatial heterogeneity; coastal zone; Baltic Sea 


\section{Introduction}

The rapid rates of global biodiversity loss and the serious anthropogenic pressures currently affecting our ecosystems (climate change, eutrophication, pollution, habitat loss), have increased the interest in and importance of understanding the role of biodiversity for ecosystem functioning (Vitousek et al., 1997; Halpern et al., 2008; Cardinale et al., 2012). The way biodiversity contributes to ecosystem functioning can be strongly controlled by environmental context, however, complicating our ability to generalize on the role of biodiversity. It is challenging to assess the relative importance of biodiversity and environmental variables for ecosystem functioning in natural ecosystems, because the functioning of these systems is regulated by many abiotic and biotic factors that are intertwined and therefore difficult to separate and control. Thus, most of the knowledge we have regarding these relationships has derived from laboratory experiments (Snelgrove et al., 2014; Gamfeldt et al., 2015). In most biodiversity-ecosystem functioning (BEF) studies to date, artificially assembled macrofauna communities have generally been investigated, which means that effects of natural species interactions, as well as spatial and temporal variation within the faunal communities and environmental conditions are not included (e.g. Gamfeldt et al., 2015). Species loss is not random, which is an aspect often neglected when using artificial communities in experiments (Larsen et al., 2005).

Additionally, most studies have concentrated only on the effects of number of species for ecosystem functioning, while other attributes of biodiversity might be as important or even more important (i.e. dominance patterns, species identity or traits like body size, Norkko et al., 2013; Pratt et al., 2014; Lohrer et al., 2015). Although experiments have improved through inclusion of more natural conditions and more realistic scenarios (Emmerson et al., 2001; Bulling et al., 2008; Godbold, 2008; Naeem, 2008; Solan et al., 2009), they provide only a small-scale and simplified picture of the complex natural systems. Therefore, the recent development within this field of research, with increasing numbers of observational field studies regarding BEF relationships, is extremely important (e.g. Hiddink et al., 2009; Needham et al., 2011; Villnäs et al., 2013; Pratt et al., 2014; Lohrer et al., 2015; Norkko et al., 2015; Gammal et al., 2017; Thrush et al., 2017). While collective evidence to date, from small-scale laboratory studies to broader field studies, all suggest that biodiversity indeed is central for ecosystem functioning, the role of environmental context in driving these relationships remains unclear.

In marine ecosystems, the benthic macrofauna is important for ecosystem functioning, and not least for the nutrient recycling processes at the seafloor. The activities of the benthic macrofauna in soft sediments are to a great extent affecting the microbial-driven biogeochemical processes responsible for nutrient recycling in the sediments (e.g. Bertics and Ziebis, 2010). Through their bioturbation and feeding behaviors, they have both indirect and direct effects on the organic matter mineralization processes. The macrofauna induce particle and solute transport for example due to their movement in search for food or building and maintenance of burrows, which affects the distribution of resources for the microbial community, as well as the oxygen and redox conditions within the sediments (Aller and Aller, 1998; 
Kristensen et al., 2012). Additionally, they have direct effects on the organic matter mineralization and nutrient recycling due to feeding, egestion and excretion (Gibbs et al., 2005; Sereda and Hudson, 2011; Vanni and McIntyre, 2016).

The activity of macrofaunal communities and their importance for nutrient recycling processes are, however, likely to vary between habitats and with changing environmental conditions, although this has not been well quantified. The structure of benthic macrofauna communities may be modified with changed grain size and organic matter input (Pearson and Rosenberg, 1978; Thrush et al., 2003; Pratt et al., 2014). Additionally, benthic macrofaunal communities have been shown to be richer (i.e. higher abundance and number of species) in vegetated habitats than in bare sediments (Boström and Bonsdorff, 1997; Fredriksen et al., 2010; Bernard et al., 2014). The interactions between macrofauna and their surrounding environment may also change their contribution to the nutrient recycling processes at the sediment-water interface in different habitats. Species can express different behaviors in different sediments, depending on grain size and organic content (Needham et al., 2011) or food supply (Riisgård and Kamermans, 2001), as well as, the density of the vegetation (Bernard et al., 2014). The same behavior may, however, also have varying effects on ecosystem functioning in different sediments, due to the different nature of physical water flow in cohesive and non-cohesive sediments (Mermillod-Blondin and Rosenberg, 2006). The potentially strong context dependency and the changing environmental conditions between habitats, thus, makes prediction of biodiversity-ecosystem functioning relationships in heterogeneous coastal environments very challenging.

Predicting BEF relationships is especially challenging in near-shore waters that are highly heterogeneous with a mosaic of habitats. Nevertheless it is imperative that we improve our ability to predict changes in these relationships since coastal areas provide many vital ecosystem functions (e.g., primary production and nutrient cycling) and services (e.g. food provision and recreational opportunities, Levin et al., 2001; Barbier et al., 2011; Snelgrove et al., 2014), while at the same time facing ever-increasing pressure from human activities. The aim of this field study was to assess the effects of biological and environmental factors on ecosystem functioning while including natural variability and complexity of the seascape in a coastal archipelago area. The specific aims were to asses 1) which variables are important for ecosystem functioning in the heterogeneous coastal zone, with special emphasis on the importance of the benthic macrofaunal communities, and 2) if the biodiversity-ecosystem function relationships are similar across different sediment types and vegetation cover. Sediment types from silt to coarse sand with varying vegetation cover were included in the study. As a measure of ecosystem functioning we used oxygen consumption and nutrient fluxes, since they represent the net effect of physical and biogeochemical processes that affect the solute exchange across the sediment-water interface. The biodiversity of the macrofaunal communities was described by species identity, number of species, abundance and biomass, as well as body size. Communities with higher abundance and number of species were predicted to occur in 
coarser sediments and those with greater vegetation cover. Additionally, we predicted that the effects of the macrofauna on the solute fluxes would decrease along the sedimentary gradient from fine to coarser sediments, due to the physical advection effects being stronger in more permeable sediments (MermillodBlondin and Rosenberg, 2006; Huettel et al., 2014).

\section{Methods}

\section{Study area and sampling}

To investigate biodiversity-ecosystem functioning relationships across habitat-types we sampled benthic macrofauna and measured oxygen and nutrient fluxes at 18 sites (Fig. 1). The sites were chosen to encompass the natural variability of habitats in the complex archipelago area close to the Hanko-peninsula, Finland, northern Baltic Sea. The shallow coastal zone in this area is heterogeneous with a mosaic of islands forming a complex labyrinthine seascape of different habitats, from very exposed to very sheltered areas, with rocky habitats interspersed by sandy and muddy substrates, and varying types of aquatic macrovegetation. The water depths in the archipelago area are generally below $40 \mathrm{~m}$, including also very shallow areas $(<5 \mathrm{~m})$, which are the most productive. The abundance of the soft-sediment macrofaunal communities is dominated by the polychaetes Hediste diversicolor, Marenzelleria spp. and Pygospio elegans, and the bivalves Macoma balthica and Cerastoderma glaucum, as well as the gastropods Hydrobiidae. Seasonality is a strong driver in the archipelago and the area is usually ice covered during winter time.

The sampling sites were spread out over a distance of approximately $20 \mathrm{~km}$, and encompassed a gradient of grain size and sediment organic matter content. The depth range was $1.7-3.9 \mathrm{~m}$ and the salinity was 5.1-5.7. The sampling occurred in late summer, 6 Aug-8 Sept 2014, at the peak of the productive season (authors' unpublished data). At each site six intact sediment cores (internal diam. $8.4 \mathrm{~cm}$, approximately 15 $\mathrm{cm}$ deep $+15 \mathrm{~cm}$ of bottom water, approx. $830 \mathrm{ml}+830 \mathrm{ml}$ ) were collected along a $20 \mathrm{~m}$ transect using SCUBA-diving. Within each site the sediment cores were collected from different types of patches (bare/vegetated) in order to include the maximum within-site variation of vegetation cover. The habitat around every core was thoroughly characterized: surface sediment samples were collected with cut-off syringes (internal diam. $3.5 \mathrm{~cm})$ around each core $(0-0.5 \mathrm{~cm}$ analyzed for organic matter and chlorophyll $a$ concentration ( $\mathrm{Chl} a$ ), and 0-3 cm analyzed for grain size). Each transect was filmed, to allow characterization of the vegetation (total cover, species-specific cover, maximum shoot height, distance to next patch, visible cover of microphytobenthos and drifting algae, amount of shell fragments on the sediment surface (classified 1-3)) over increasing spatial scales $\left(0.25,0.75,1.25,1.75,2.25 \mathrm{~m}^{2}\right)$ around each core. The oxygen concentration and temperature of the bottom water was measured in the field with an optical 
dissolved oxygen meter (Ysi ProODO), whereas the salinity was measured in the laboratory with a conductivity meter (VWR EC300).

Immediately after sampling the cores were taken into the laboratory. Five cores ( $\mathrm{n}=5$ for all sites except 1,6 and 11 , where $n=4$ and site 16 , where $n=3$ ) were incubated for measurement of solute fluxes and from the sixth core a profile of porewater nutrient concentrations $(1,3,5,10 \mathrm{~cm}$ sediment depths) was extracted with rhizon porewater samplers. Incubation and flux measurements were performed in the laboratory under dark conditions at in situ temperatures. The cores were left for 1-h acclimatization prior to the 3-h incubations. The overlying water was exchanged with bottom water collected at the site before the start of every incubation, and to prevent disturbance of the sediment surface during the exchange of water a baffle was used. Overlying water in each core was manually stirred every 30 minutes during the incubation ensuring sufficient mixing while avoiding sediment resuspension in the finer sediments or inducing porewater advection in the coarser sediments. The oxygen concentration in the cores during all incubations always remained higher than $6 \mathrm{mg} \mathrm{l}^{-1}$. For estimation of the solute fluxes $\left(\mathrm{O}_{2}, \mathrm{NO}_{3}{ }^{-}+\mathrm{NO}_{2}{ }^{-}, \mathrm{NH}_{4}{ }^{+}, \mathrm{PO}_{4}{ }^{3-}, \mathrm{Si}\right)$ water samples were taken at the start and the end of the incubations. Given the known water volume, surface area and incubation time, the solute fluxes were calculated and expressed in $\mu \mathrm{mol} \mathrm{m} \mathrm{m}^{-2} \mathrm{~h}^{-1}$ and $\mathrm{mg} \mathrm{m}^{-2} \mathrm{~h}^{-1}$. After the incubations the cores were sieved and the fauna preserved $(0.5-\mathrm{mm}$ sieve, $70 \%$ ethanol) to obtain core-specific benthic macrofauna data.

\section{Laboratory analyses}

Dissolved oxygen concentrations $\left(\mathrm{mg}^{-1}\right)$ were determined by the Winkler procedure. Water samples for analysis of nutrient concentrations were filtered (Whatman GF/F) and frozen until analysis. Nutrients in the water samples and the porewater samples, were analyzed with a nutrient auto analyzer (Thermo Scientific Aquakem 250; $\left.\mathrm{NO}_{2}{ }^{-}+\mathrm{NO}_{3}{ }^{-}, \mathrm{PO}_{4}{ }^{3-}, \mathrm{Si}\right)$ or manually $\left(\mathrm{NH}_{4}{ }^{+}\right.$, Koroleff 1979).

Samples for sediment characterization were frozen until further processing. The grain size samples were treated with hydrogen peroxide $\left(\mathrm{H}_{2} \mathrm{O}_{2}, 6 \%\right)$ to dissolve organic material, then sieved on a wet column $(63,125,250,500,1000,2000 \mu \mathrm{m})$. Sediment for each grain size fraction was then dried, and the percentage of dry weight of each fraction calculated. Homogenized surface sediment $(0-0.5 \mathrm{~cm})$ was analyzed for organic matter content $(\mathrm{OM})$ as loss on ignition $\left(3 \mathrm{~h}\right.$ at $\left.500^{\circ} \mathrm{C}\right)$. Freeze-dried surface sediment was analyzed spectrophotometrically for chlorophyll $a(\mathrm{Chl} a)$ and phaeophytin content (extraction in $90 \%$ acetone).

The macrofaunal samples were analyzed under the microscope to determine number of species (lowest taxonomic level possible, hereafter referred to as species), abundance, individual body size and biomass (blotted wet weight). The bivalves (Macoma balthica, Cerastoderma glaucum and Mya 
arenaria), which dominate biomass, were split into large $(>5 \mathrm{~mm})$ and small $(<5 \mathrm{~mm})$ individuals to facilitate investigation of potential size-dependent effects on ecosystem functioning. After the fauna was sorted, the residual sample was sieved again through an 8-mm sieve to retain the larger items present in the cores for additional characterization of the sedimentary habitats. All items were sorted into roots (dead or alive roots and rhizomes, as well as other plant detritus), shells or pebbles and their volume quantified through liquid displacement.

\section{Statistical analyses}

We used multivariate statistics to explore our results. PCA-analysis (PRIMER v7) on the raw data of the grain size fractions was used to identify groups, and CLUSTER-analysis with SIMPROF-test was used to determine the appropriate split of the grain size data into groups (coarse, medium and fine sediment). To describe differences in the macrofauna communities (species abundance and biomass), we used non-metric multidimensional scaling (nMDS PRIMER v7, Clarke and Gorley, 2015), based on the Bray-Curtis similarity index. Dummy species were included in the analyses (added to all samples with the same value) to enable inclusion of one core without fauna (Clarke et al., 2014). Additionally, one-way permutational analysis of variances (PERMANOVA, PRIMER v7) and associated dispersion analysis (PERMDISP, PRIMER v7) were used to determine the significance of differences in community abundance and biomass between the sediment types, and SIMPER-analysis to further investigate the species defining differences between communities (i.e. which species are contributing to the between-group differences). Only macrofauna species present in more than $33 \%$ of the cores have been used in the statistical analyses, thus focusing on the most common species. PERMANOVA was also used to identify differences in the multivariate solute fluxes $\left(\mathrm{O}_{2}, \mathrm{NH}_{4}{ }^{+}, \mathrm{PO}_{4}{ }^{3-}, \mathrm{Si}\right)$ between sites and between the sediment types, as well as to examine differences between the sediment types in the individual solute fluxes. $\mathrm{NO}_{2}{ }^{-}+\mathrm{NO}_{3}{ }^{-}$-fluxes were excluded from all analyses since most bottom-water concentrations were below the detection limits. Twoway PERMANOVA was used to identify differences in the individual porewater concentrations $\left(\mathrm{NO}_{2}{ }^{-}+\right.$ $\mathrm{NO}_{3}{ }^{-}, \mathrm{NH}_{4}{ }^{+}, \mathrm{PO}_{4}{ }^{3-}, \mathrm{Si}$ ) between the sediment types, when also including the sediment depth. The interaction factor between sediment type and sediment depth was not significant for any solute profile, consequently only the significant differences between sediment types were reported.

Distance-based linear models (DistLM in PERMANOVA+ for PRIMER v7, Anderson et al., 2008) were used to examine the influence of environmental and biological variables on a multivariate measure of the solute fluxes across the sediment-water interface (i.e. our measure of ecosystem functioning). The solute fluxes were combined to a multivariate proxy for ecosystem functioning, because the individual solute fluxes are very spatially variable and affected differently by environmental and biological factors. This facilitates detection of robust biodiversity-ecosystem functioning relationships across the diverse set of environmental contexts investigated (Link et al., 2013; Villnäs et al., 2013; Norkko et al., 2015). DistLM is a 
type of multiple linear regression model performed on multivariate response data in order to determine how much of the variation can be explained by predictor variables. We linked environmental and macrofaunal community data to the measured solute fluxes $\left(\mathrm{O}_{2}, \mathrm{NH}_{4}{ }^{+}, \mathrm{PO}_{4}{ }^{3-}, \mathrm{Si}\right)$. The macrofaunal predictors were included in the analyses to account for faunal metabolism and bioturbation effects on the solute fluxes.

In total, four sets of DistLM-analyses were conducted, one for the whole gradient (i), and one for each sediment type (ii-iv, i.e. the groups based on the cluster analysis described above). One core from site 13 was not clustered into any sediment group and consequently this core is only included in analyses with all cores. Environmental predictors included in all analyses (i-iv) were depth, temperature, OM, roots, pebbles (>8 mm), dead shells in the sediment, and cover of vegetation, microphytobenthos and drifting algae. Additionally, median grain size (D50) was included in the analysis of all cores (i). Prior to statistical analysis, the roots, pebbles and shells in the sediments were standardized in relation to the volume of sediment in the individual cores. The macrofaunal community data included was total number of species present in each core, and species abundance and biomass of the species present in more than $33 \%$ of the cores within each group. Bottom-water oxygen concentration and salinity were not included since they were considered to be within the same range in all groups. Collinearity between the predictors were assessed through Pearson's correlations and Chl $a$ was not included due to strong correlation with $\mathrm{OM}\left(\mathrm{r}^{2}=0.91\right)$. The distribution of all variables was examined and if needed, transformed prior to each analysis (transformations used were $\log _{10}(\mathrm{x}+1)$ and square-root $)$.

Flux data $\left(\mathrm{NH}_{4}{ }^{+}, \mathrm{PO}_{4}{ }^{3-}, \mathrm{Si}, \mathrm{O}_{2}\right)$ were normalized to ensure equal importance of all fluxes (by subtracting the mean and dividing by the standard deviation for each variable) before resemblance matrices based on between-sample similarities of Euclidean distances were created. An AICc stopping criterion and step-wise selection were used to determine the relative importance of predictors. The marginal test indicates the proportion of the variation the predictor accounts for alone, while the results from the sequential test indicate the proportion added by the predictor to the cumulative total proportion explained.

\section{Results}

\section{Sedimentary environment}

The sites were on a gradient of grain size, the range of median grain size (D50) was 21-845 $\mu \mathrm{m}$ with a mean of $275 \mu \mathrm{m}$ and the range of organic matter content (OM) was $0.2-16.8 \%$ with a mean of $2.2 \%$ (Table 1 ). Based on a cluster analysis on the different grain size fractions followed by a PCA we identified three distinctive groups; coarse, medium and fine sediments, corresponding to coarse to fine sand, fine to very fine sand, and silt on the Wentworth scale (Wentworth, 1922, Fig. 2). The average D50-values for the coarse, 
medium and fine sediments were 400, 150 and $40 \mu \mathrm{m}$, respectively (Table 1). The average OM content and $\mathrm{Chl} a$ in the top $0.5 \mathrm{~cm}$ surface sediment was as expected lower in the coarse $\left(0.7 \%\right.$ and $18 \mu \mathrm{g} \mathrm{g}^{-1}$ sed., respectively) and medium sediments ( $0.8 \%$ and $15 \mu \mathrm{g} \mathrm{g}^{-1}$ sed.) than in the fine sediments ( $7 \%$ and $40 \mu \mathrm{g} \mathrm{g}^{-1}$ sed.), while the ranges in depth, and bottom-water temperature, salinity and oxygen concentrations were similar in all groups.

\section{Biological communities}

In total 16 benthic macrofauna species/taxa were observed, with a mean of 6 species in each core. The range of average total abundance at the sites was 1900-16 000 ind. $\mathrm{m}^{-2}$ (Appendix 1), and for average total biomass 7-1 $200 \mathrm{~g}$ wwt $\mathrm{m}^{-2}$ (Appendix 2). The dominant taxa in terms of abundance were Hydrobiidae, $M$. balthica, Oligochaeta, Marenzelleria spp. and H. diversicolor (together representing on average $80 \%$ of total abundance in each sample), while biomass was dominated by M. balthica, Cerastoderma glaucum, Mya arenaria, H. diversicolor and Marenzelleria spp. (together representing on average $80 \%$ of total biomass in each sample). The distribution of Mya arenaria is highly stochastic and in our data M. arenaria was only observed in a few samples within the coarse-sediment group (Table 1). Therefore, even if it can dominate the biomass when present, it was excluded from the statistical analyses. Hereafter, only results including the abundance and biomass of the most common species are presented (9 species that were present in more than $33 \%$ of the cores).

The macrofauna community structures were significantly different between the sediment types (PERMANOVA: species abundance $F=7.24, p=0.0001$; species biomass $F=3.59, p=0.0009$, MDS Fig. 3 , Appendix 3), the variability within the groups was however similar (PERMDISP $p>0.05$ ). The averages of the core-specific total abundances were 11000,6700 and 3600 ind. $\mathrm{m}^{-2}$ in the coarse, medium and fine groups respectively (Table 1). Regarding biomass, the same patterns were observed with averages of 131, 103 and $35 \mathrm{~g} \mathrm{wwt} \mathrm{m}^{-2}$, respectively (Table 1). The average number of species observed in the cores decreased towards the finer sediments (coarse 7, medium 5 and fine 4, Table 1). Macrofauna community structure in the coarse group differed from the communities in the medium sediments (PERMANOVA pairwise test: abundance, average dissimilarity $61 \%, t=2.39, p=0.0003$, biomass n.s., Appendix 3) and the communities in the fine sediments (PERMANOVA pairwise test: abundance, average dissimilarity $67 \%, \mathrm{t}=$ $3.46, \mathrm{p}=0.0001$, biomass: average dissimilarity $81 \%, \mathrm{t}=2.54, \mathrm{p}=0.0002$ ), and the communities in the medium sediments differed from the communities in fine sediments (PERMANOVA pairwise test: abundance n.s., biomass: average dissimilarity $82 \%, \mathrm{t}=1.63, \mathrm{p}=0.025$ ). Almost all species were present in all the different groups, but the numbers of individuals and the species biomass were generally higher in the coarse group. The taxa contributing most to the inter-group differences were Hydrobiidae (Gastropoda), the bivalve Macoma balthica, oligochaetes, as well as the polychaetes Marenzelleria spp. and Hediste diversicolor (SIMPER-analysis, Appendix 4 and 5). All species' abundance and biomass were highest in the 
coarse sediments and second highest in the medium sediments, except for the average abundance and biomass of $M$. balthica that were highest in medium sediments, and the biomass of $H$. diversicolor that was highest in the fine sediments.

At every site samples were collected from bare sediment patches as well as from patches with different vegetation cover, which means that zero-values of vegetation cover were obtained from all sites, but overall there was denser vegetation in the coarse and medium sediment-groups (Table 1). All observed species of macrovegetation occurred in the coarse and medium sediments, except for Zostera marina that only occurred in the coarse sediments. Sparsely distributed Stuckenia pectinata, Potamogeton perfoliatus and Myriophyllum spp. were characteristic for the fine sediments.

\section{Ecosystem functioning}

Ecosystem functioning was defined as a multivariate measure of oxygen and nutrient fluxes across the sediment-water interface. This multivariate measure was very variable along the gradient (PERMDISP $\mathrm{p}>$ 0.05, PERMANOVA: overall multivariate differences between sites $\mathrm{F}=2.63, \mathrm{p}=0.0009$, Appendix 6), but there were, however, no significant multivariate differences in the solute fluxes between the three sediment types, due to large variation within all sediment groups (PERMDISP $\mathrm{p}>0.05$, PERMANOVA: $\mathrm{F}=2.19, \mathrm{p}=$ 0.063, Appendix 7). Separately, the phosphate and oxygen fluxes were the only fluxes to show significant differences between the sediment types (Fig. 4). The phosphate flux was higher in the medium and fine sediments than in the coarse sediments, while the oxygen flux was higher in the fine than in the coarse sediments (PERMANOVA: $\mathrm{PO}_{4}{ }^{3-}$-flux: overall $\mathrm{F}=5.6, \mathrm{p}=0.007$, pairwise-test coarse-medium $\mathrm{t}=3.39, \mathrm{p}=$ 0.002 , coarse-fine $\mathrm{t}=2.65, \mathrm{p}=0.011, \mathrm{O}_{2}$-flux: overall $\mathrm{F}=2.5, \mathrm{p}=0.09$, pairwise-test coarse-fine $\mathrm{t}=2.03, \mathrm{p}$ $=0.049$, Appendix 7). $\mathrm{NO}_{2}{ }^{-}+\mathrm{NO}_{3}{ }^{-}$-concentrations in the bottom water were extremely low (Appendix 8) and mostly under the detection limit, therefore the $\mathrm{NO}_{2}{ }^{-}+\mathrm{NO}_{3}{ }^{-}$-fluxes were excluded from all data analyses. The porewater profiles were also variable between sites, but the mean solute concentrations were generally higher in the fine sediments. Significant differences between the sediment types were, however, only observed in the porewater concentrations of phosphate and silicate; the concentrations increased from the coarse, to the medium and to the fine sediments (PERMANOVA: $\mathrm{PO}_{4}{ }^{3-}$ : overall $\mathrm{F}=33.3, \mathrm{p}=0.0001$, pairwise-test coarse-fine $\mathrm{t}=8.02, \mathrm{p}=0.0001$, coarse-medium $\mathrm{t}=2.46, \mathrm{p}=0.020$, medium-fine $\mathrm{t}=3.16, \mathrm{p}=$ 0.005 , Si: overall $\mathrm{F}=27.0, \mathrm{p}=0.0001$, pairwise-test coarse-fine sediments $\mathrm{t}=7.16, \mathrm{p}=0.0001$, coarsemedium $\mathrm{t}=2.30, \mathrm{p}=0.023$, medium-fine $\mathrm{t}=2.95, \mathrm{p}=0.007$; Appendix 9).

To assess the importance of different types of factors (abiotic vs. biotic) for ecosystem functioning, we linked variables describing the environment and macrofauna communities with the measured multivariate solute fluxes, (i) on a larger scale, over the whole sampled archipelago, as well as in (ii-iv) the three different sediment types (Table 2). On the archipelago scale (i), a total of $45 \%$ of the total variation in 
multivariate solute fluxes could be explained; 3 species of macrofauna accounted cumulatively for $25 \%$ of the total variation explained, while environmental variables cumulatively added another $20 \%$ (Table $2 \mathrm{i}$ and Fig. 5). The macrofauna species contributing to the cumulative explanation were the biomass of $H$. diversicolor (21\%) and small C. glaucum (2\%), as well as the abundance of large M. balthica (2\%). The most important environmental variables adding to the cumulative explanation were temperature $(6 \%)$, roots (5\%), OM-content (5\%), and vegetation cover around the core (3\%).

In order to investigate the important drivers of ecosystem functioning in different habitats, we did the same analysis, but on the data split into the three sediment groups (Table 2ii-iv). With this split a higher proportion of the total variance could be explained, also highlighting distinct differences between the sediment types. In the coarse sediments (ii) the included variables explained a total of $52 \%$ of the variation in the multivariate solute fluxes, and the amount of roots alone explained $23 \%$ of the total variation. Depth and vegetation cover added $7 \%$ and $4 \%$, respectively, while the rest of the variation explained (19\%) was accounted for by the benthic macrofauna. The contributing fauna were the biomass of $H$. diversicolor and Marenzelleria spp., and the abundance of small M. balthica. In the medium sediments (iii) only fauna was chosen into the model; abundance of $H$. diversicolor and small $M$. balthica, explaining a total of $69 \%$ of the variation in the multivariate solute fluxes. In the fine sediments (iv) a total of $76 \%$ of the variation was explained; fauna cumulatively accounted for $51 \%$ of the total variation explained, while the rest was explained by the cover of microphytobenthos around the core (25\%). The faunal variables contributing to the explanation was the biomass of $H$. diversicolor and Hydrobiidae.

Including environmental variables of different scales around the cores (cover of vegetation, microphytobenthos, drifting algae, and shell fragments on the sediment surface within $0.75,1.25,1.75,2.25$ $\mathrm{m}^{2}$ around each core) did not add explanatory power. Consequently, only the results of analyses including the scale of $0.25 \mathrm{~m}^{2}$ have been presented.

\section{Discussion}

We investigated the variability of ecosystem functioning in relation to environmental and biological drivers across natural habitats in a complex and heterogeneous coastal area. A broad gradient of sediment grain size and organic matter content was encompassed, as well as the variable macrovegetation present in the habitats (patchiness and species composition). The resident macrofaunal communities changed, as expected, along the grain size gradient, with richer communities (higher abundance, biomass and number of species) in the coarser sediments with lower organic matter content and with higher vegetation cover (Table 1). The macrofaunal communities, and especially a few key species had a large impact on the nutrient transformation and retention processes (Table 2). Across all sediment types, the macrofauna accounted for $25 \%$ of the 
variability in the solute fluxes; within sediment types, it accounted for up to 69\%. These results support the general consensus that benthic macrofauna is important for ecosystem functioning, especially the mineralization processes at the sediment-water interface through their role as ecosystem engineers. Our results also, however, highlight the large context-dependence and complex relationships between ecosystem functioning and biodiversity prevailing in nature. A majority of the BEF studies to date, have been shortterm and small-scale experiments conducted under highly controlled conditions with artificial macrofauna communities, consequently omitting the natural variability and spatial heterogeneity, which clearly play an important role in modifying BEF relationships. The quest for mechanistic insight has come at the expense of realism, which further emphasizes the importance of field studies like this one (Bulling et al., 2008; Snelgrove et al., 2014).

While we found that benthic macrofaunal communities were significantly different between the sediment types, somewhat surprisingly, no differences in our measure of ecosystem functioning (multivariate solute fluxes) could be observed between the sediment types. This was likely due to the fact that only oxygen consumption and phosphate effluxes were significantly higher in the fine sediments, while the other solute fluxes were highly variable within all groups. The higher levels of organic matter content in the fine sediments likely contributed to higher oxygen consumption in the fine sediments (Glud, 2008; Aller, 2014). Furthermore, the lack of natural water currents during chamber incubations may have caused an underestimation of oxygen uptake in the coarser sediments (McGinnis et al., 2014). The significantly higher phosphate concentration in the porewater of the fine sediments mirrors the higher effluxes in this sediment type. The lack of significant differences in the multivariate solute fluxes between the groups, may also partly be due to sampling effects, as coring inevitably disturbs the chemical gradients around the core edges to some extent. Careful coring by SCUBA has, however, been shown to cause less disturbance than surfacebased gravity coring (Mogg et al., 2017). Additionally, it also shows that it is not grain size alone that determines the fluxes at the sediment-water interface.

When examining the important faunal predictors for multivariate solute fluxes (ecosystem function) we found that the abundant polychaete Hediste diversicolor played a central role, together with the bivalves Macoma balthica and Cerastoderma glaucum. H. diversicolor is a gallery diffusor that has been described as a carnivore and a scavenger, and being able to switch between suspension and surface-deposit feeding modes depending on the conditions (Riisgård and Kamermans, 2001). M. balthica is a biodiffusor that also has been observed to switch between suspension and deposit feeding (Riisgård and Kamermans 2001), whereas $C$. glaucum is a filtering biodiffusor mostly located in the surface sediments (Urban-Malinga et al., 2014). Especially, H. diversicolor is an active bioirrigator and an efficient particle reworker with impacts on the biogeochemical processes and conditions within the sediments (e.g. Christensen et al., 2000; Hedman et al., 2011; Urban-Malinga et al., 2014). The environmental variables included in the model were the amount of root structures, OM and vegetation cover, as well as temperature. Temperature and organic 
matter directly affect the microbial processes and the faunal activity, and therefore also the solute fluxes. Additionally, the organic matter content contributes to the pool of raw material for mineralization processes in the sediments (Moodley et al., 2005). The amount of root structures and macrovegetation may, however, have complex effects, both direct and indirect, on the nutrient dynamics. While not accounted for here, their nutrient uptake and oxygenation of both bottom water and sediments naturally have direct impact on nutrient recycling processes (Caffrey and Kemp, 1991), as also demonstrated in the same area by Gustafsson and Norkko (2016). The above ground structures, in turn, enhance the entrapment of suspended particles, which consequently increases the organic matter input in vegetated habitats (Fonseca and Fisher, 1986; Meadows et al., 2012). The vegetation also affects the structure of the benthic macrofauna communities, by, for example, providing shelter and trapping suspended particles which, together, with enhanced decay of plant detritus, contributes to a more abundant and stable food source for the macrofauna (Castel et al., 1989; Reise, 2002; Bernard et al., 2014). Additionally, the bioturbation activities of the macrofauna have been shown to be lower in vegetated habitats, for example due to sediment compaction or below-ground structures, such as roots and rhizomes limiting the movement of large bioturbators (e.g. Berkenbusch et al., 2007; Bernard et al., 2014).

Ecosystem functioning is thus affected by many environmental and biological properties, but the relationship between biodiversity and ecosystem functioning is mediated by the habitat. Our results suggest that specific environmental properties are affecting the functioning more in the coarse sediments, whereas certain benthic macrofauna species are more important drivers in the medium and fine sediments (Table 2ii-iv). These results fit well in with the hypotheses that the bioturbation activities of the benthic macrofauna have large effects on the microbial-driven biogeochemical processes in diffusive-dominated sediments, whereas the natural physical water flow masks the faunal effects in more advection-dominated sediments (e.g. Kristensen and Kostka, 2005; Mermillod-Blondin and Rosenberg, 2006; Braeckman et al., 2014; Huettel et al., 2014). These relationships may, however, be further complicated by other environmental properties in addition to grain size. In the coarse sediments, for example, the amount of roots, rhizomes, and plant parts accounted for a large part of the variation explained in the solute fluxes, and the same factors were also important predictors of bioturbation metrics measured concurrently at the same sites (Unpublished manuscript: Bernard G, Gammal J., Järnström M., Norkko J., Norkko A.). This may suggest that the roots, in addition to direct effects, had indirect effects on the solute fluxes through for example spatially restricting the macrofaunal activities (Bernard et al., 2014). The included variables, however, explained less of the variance in the coarse sediments compared to medium and fine sediments, likely due to the lack of consideration of natural water currents and waves, and thus advective pore-water flow which influence solute fluxes in natural sediments (e.g. Janssen et al. 2005).

In our system, biomass and abundance of only a few of the dominant species contributed to the best models; these were principally the key bioturbation species that are widely distributed in all shallow 
habitats. The same major species were thus important for the measured ecosystem functioning both on a larger scale across all sites and in the investigated sediment types, while the number of species did not add any explanatory power. Earlier research has commonly focused on the role of species richness for ecosystem functioning, but with varying results and it has often been difficult to capture the key properties of biodiversity affecting ecosystem functioning (Stachowicz et al., 2007; Reiss et al., 2009). Therefore, it has been hypothesized that species identity can be central for ecosystem functioning and that dominance of some key species may be very important (Chapin III et al., 1997; Emmerson et al., 2001; Pratt et al., 2014; Lohrer et al., 2015), especially in species-poor systems like the Baltic Sea (Norkko et al., 2013; Norkko et al., 2015). Species are also commonly grouped together or characterized according to their biological or functional traits, to better describe their role for the ecosystem functioning (Villnäs et al., 2017). For example, a recent study exploring intra-specific variation in size structure and its potential role in ecosystem function, demonstrated that large bivalves completely dominated solute fluxes (Norkko et al., 2013). Individual size and distribution of large species in the community has, indeed, been suggested as a key variable influencing ecosystem functioning (Solan et al., 2004; Thrush et al., 2006). In the present study, we had to exclude the large bivalve-species Mya arenaria from the statistical analyses due to its stochastic distribution, consequently we may have lost some faunal influence on the ecosystem functioning. The abundance or biomass of the bivalve was, however, not significant even in a model based on only samples containing $M$. arenaria, which suggested that the exclusion of the few bivalves has not markedly affected the results in this particular study. Furthermore, there is evidence suggesting that one species or trait can play different roles in different habitats (Riisgård and Kamermans, 2001; Mermillod-Blondin and Rosenberg, 2006; Needham et al., 2011), and their impact on ecosystem functioning might thus not be consistent. Additionally, recent research has shown that many different measures of biodiversity (e.g. community abundance, functional richness but also distribution of specific species) may be needed if we want to be able to predict ecosystem functioning and the natural multifunctionality of ecosystems, especially since the relationships may also change with altered environmental conditions (Thrush et al., 2017).

Marine ecosystems and their functioning vary between regions (e.g. Norkko et al., 2015; Bourgeois et al., 2017), habitat types (Needham et al., 2011; Braeckman et al., 2014; Attard et al., 2015), and seasons (Bourgeois et al., 2017; Kauppi et al., 2017), as well as with changing environmental conditions due to anthropogenic disturbance (e.g. climate change, sedimentation, eutrophication and hypoxia, Lohrer et al., 2004; Norkko et al., 2015; Gammal et al., 2017), which makes it difficult to generalize and predict ecosystem function in nature. One way of increasing the understanding of the natural variability is to sample along environmental gradients (Hewitt et al., 2007; Snelgrove et al., 2014), since these studies, even though observational, enhance our knowledge of the complex links and feedbacks in natural ecosystems. Gradient studies in soil ecosystems have, for example, resulted in valuable knowledge regarding environmental factors structuring the soil communities. This has enhanced the understanding of responses of soil communities to for example climate change, e.g. altered soil water availability, and the potential consequences for 
decomposition and nutrient recycling processes in soil systems (Virginia and Wall, 1999; Poage et al., 2008; Wall et al., 2008; Sylvain et al., 2014). The wide grain size gradient we sampled gave us an opportunity to quantify the variability in environmental conditions, biodiversity, ecosystem functioning and their relationships in a diverse set of habitats. In this system, a few abundant macrofauna species were important along the whole gradient and in the investigated sediment types, but with varying explanatory power in the different environments. Even though there was lower abundance, biomass and number of species in the medium and fine sediments, the same species had a significant influence on the solute fluxes, which suggests that predicting the functioning in different habitats directly based on the amount of fauna or specific traits expressed may not be expedient; consideration of environmental context will be equally important. The variability in environmental context (i.e. grain size, OM and vegetation) and benthic macrofauna communities is a challenging aspect when trying to understand and model the links and feedbacks that underpin ecosystem functioning and consequently the ecosystem services we rely on. It is thus important for future research to further clarify biodiversity and ecosystem functioning relationships at different spatial and temporal scales in different environments, while accounting for different descriptors of biodiversity, if we are going to be able to predict the consequences of the environmental changes and implement insightful management strategies.

\section{Acknowledgements}

This study was funded by Walter and Andrée de Nottbeck Foundation (JG, GB), and the BONUS COCOA project, which was supported by BONUS (Art 185), funded jointly by the EU and the Academy of Finland (AN), and the University of Helsinki (3-year grant to JN). We sincerely thank Judi Hewitt for valuable advice on statistical analyses, Emmi Hänninen for video analyses, and Hanna Halonen and trainees at Tvärminne Zoological Station for valuable practical assistance.

Conflict of Interest: The authors declare that they have no conflict of interest.

\section{References}

Aller RC. 2014. Sedimentary Diagenesis, Depositional Environments, and Benthic Fluxes. Holland HD, Turekian KK, editors. Treatise on Geochemistry, Second Edition, vol. 8, pp. 293-334. Oxford: Elsevier.

Aller RC, Aller JY. 1998. The effect of biogenic irrigation intensity and solute exchange on diagenetic reaction rates in marine sediments. Journal of Marine Research 56: 905-936.

Anderson MJ, Gorley RN, Clarke KR. 2008. PERMANOVA+ for PRIMER. Guide to software and statistical methods, $214 \mathrm{pp}$.

Attard KM, Stahl H, Kamenos NA, Turner G, Burdett HL, Glud RN. 2015. Benthic oxygen exchange in a live coralline algal bed and an adjacent sandy habitat: an eddy covariance study. Marine Ecology Progress Series 535: 99-115.

Barbier EB, Hacker SD, Kennedy C, Koch EW, Stier AC, Silliman BR. 2011. The value of estuarine and coastal ecosystem services. Ecological Monographs 81: 169-193. 
Berkenbusch K, Rowden AA, Myers TE. 2007. Interactions between seagrasses and burrowing ghost shrimps and their influence on infaunal assemblages. Journal of Experimental Marine Biology and Ecology 341: 70-84.

Bernard G, Delgard ML, Maire O, Ciutat A, Lecroart P, Deflandre B, Duchêne JC, Grémare A. 2014. Comparative study of sediment particle mixing in a Zostera noltei meadow and a bare sediment mudflat. Marine Ecology Progress Series 514: 71-86.

Bertics VJ, Ziebis W. 2010. Bioturbation and the role of microniches for sulfate reduction in coastal marine sediments. Environmental Microbiology 12: 3022-3034.

Boström C, Bonsdorff E. 1997. Community structure and spatial variation of benthic invertebrates associated with Zostera marina (L) beds in the northern Baltic Sea. Journal of Sea Research 37: 153-166.

Bourgeois S, Archambault P, Witte U. 2017. Organic matter remineralization in marine sediments: A PanArctic synthesis. Global Biogeochemical Cycles 31: 190-213.

Braeckman U, Foshtomi MY, Gansbeke D, Meysman F, Soetaert K, Vincx M, Vanaverbeke J. 2014. Variable Importance of Macrofaunal Functional Biodiversity for Biogeochemical Cycling in Temperate Coastal Sediments. Ecosystems 17: 720-737.

Bulling MT, Solan M, Dyson KE, Hernandez-Milian G, Luque P, Pierce GJ, Raffaelli D, Paterson DM, White PCL. 2008. Species effects on ecosystem processes are modified by faunal responses to habitat composition. Oecologia 158: 511-520.

Caffrey JM, Kemp WM. 1991. Seasonal and spatial patterns of oxygen production, respiration and rootrhizome release in Potamogeton perfoliatus L. and Zostera marina L. Aquatic Botany 40: 109128.

Cardinale BJ, Duffy JE, Gonzalez A, Hooper DU, Perrings C, Venail P, Narwani A, Mace GM, Tilman D, Wardle DA, Kinzig AP, Daily GC, Loreau M, Grace JB, Larigauderie A, Srivastava DS, Naeem S. 2012. Biodiversity loss and its impact on humanity. Nature 486: 59-67.

Castel J, Labourg P-J, Escaravage V, Auby I, Garcia ME. 1989. Influence of seagrass beds and oyster parks on the abundance and biomass patterns of meio- and macrobenthos in tidal flats. Estuarine, Coastal and Shelf Science 28: 71-85.

Chapin III FS, Walker BH, Hobbs RJ, Hooper DU, Lawton JH, Sala OE, Tilman D. 1997. Biotic control over the functioning of ecosystems. Science 277: 500-504.

Christensen B, Vedel A, Kristensen E. 2000. Carbon and nitrogen fluxes in sediment inhabited by suspension-feeding (Nereis diversicolor) and non-suspension-feeding ( $\mathrm{N}$-virens) polychaetes. Marine Ecology Progress Series 192: 203-217.

Clarke KR, Gorley RN, Somerfield PJ, Warwick RM. 2014. Change in marine communities: an approach to statistical analysis and interpretation, 3rd edition. PRIMER-E: Plymouth.

Clarke KR, Gorley RN. 2015. PRIMER v7: User Manual/Tutorial. PRIMER-E: Plymouth.

Emmerson MC, Solan M, Emes C, Paterson DM, Raffaelli D. 2001. Consistent patterns and the idiosyncratic effects of biodiversity in marine ecosystems. Nature 411: 73-77.

Fonseca MS, Fisher JS. 1986. A comparison of canopy friction and sediment movement between four species of seagrass with reference to their ecology and restoration. Marine Ecology Progress Series 29: 15-22.

Fredriksen S, De Backer A, Boström C, Christie H. 2010. Infauna fromZostera marina L. meadows in Norway. Differences in vegetated and unvegetated areas. Marine Biology Research 6: 189200.

Gamfeldt L, Lefcheck JS, Byrnes JEK, Cardinale BJ, Duffy JE, Griffin JN. 2015. Marine biodiversity and ecosystem functioning: what's known and what's next? Oikos 124: 252-265.

Gammal J, Norkko J, Pilditch CA, Norkko A. 2017. Coastal Hypoxia and the Importance of Benthic Macrofauna Communities for Ecosystem Functioning. Estuaries and Coasts 40: 457-468.

Gibbs M, Funnell G, Pickmere S, Norkko A, Hewitt J. 2005. Benthic nutrient fluxes along an estuarine gradient: influence of the pinnid bivalve Atrina zelandica in summer. Marine Ecology Progress Series 288: 151-164.

Glud RN. 2008. Oxygen dynamics of marine sediments. Marine Biology Research 4: 243-289.

Godbold JA. 2008. Marine benthic biodiversity-ecosystem function relations in complex systems. PhD thesis, University of Aberdeen, Scotland. http://ethos.bl.uk/OrderDetails.do?uin=uk.bl.ethos.493491 
Gustafsson C, Norkko A. 2016. Not all plants are the same: Exploring metabolism and nitrogen fluxes in a benthic community composed of different aquatic plant species. Limnology and Oceanography 61: 1787-1799.

Halpern BS, Walbridge S, Selkoe KA, Kappel CV, Micheli F, D'Agrosa C, Bruno JF, Casey KS, Ebert C, Fox HE, Fujita R, Heinemann D, Lenihan HS, Madin EMP, Perry MT, Selig ER, Spalding M, Steneck R, Watson R. 2008. A Global Map of Human Impact on Marine Ecosystems. Science 319: 948-952.

Hedman JE, Gunnarsson JS, Samuelsson G, Gilbert F. 2011. Particle reworking and solute transport by the sediment-living polychaetes Marenzelleria neglecta and Hediste diversicolor. Journal of Experimental Marine Biology and Ecology 407: 294-301.

Hewitt JE, Simon F. Thrush, Paul K. Dayton, Erik Bonsdorff. 2007. The Effect of Spatial and Temporal Heterogeneity on the Design and Analysis of Empirical Studies of Scale-Dependent Systems. The American Naturalist 169: 398-408.

Hiddink JG, Davies TW, Perkins M, Machairopoulou M, Neill SP. 2009. Context dependency of relationships between biodiversity and ecosystem functioning is different for multiple ecosystem functions. Oikos 118: 1892-1900.

Huettel M, Berg P, Kostka JE. 2014. Benthic Exchange and Biogeochemical Cycling in Permeable Sediments. Annual Review of Marine Science 6: 23-51.

Janssen F, Huettel M, Witte U. 2005. Pore-water advection and solute fluxes in permeable marine sediments (II): Benthic respiration at three sandy sites with different permeabilities (German Bight, North Sea). Limnology and Oceanography 50: 779-792

Kauppi L, Norkko J, Ikonen J, Norkko A. 2017. Seasonal variability in ecosystem functions: quantifying the contribution of invasive species to nutrient cycling in coastal ecosystems. Marine Ecology Progress Series 572: 193-207.

Koroleff F. 1976. Total and organic nitrogen. Grasshoff K. editor. Methods of seawater analysis. New York, Verlag Chemie.Kristensen E, Kostka JE. 2005. Macrofaunal Burrows and Irrigation in Marine Sediment: Microbiological and Biogeochemical Interactions. Kristensen E, Haese, R.R., Kostka, J.E. editor. Interactions Between Macro- and Microorganisms in Marine Sediments. Washington: American Geophysical Union.

Kristensen E, Penha-Lopes G, Delefosse M, Valdemarsen T, Quintana CO, Banta GT. 2012. What is bioturbation? The need for a precise definition for fauna in aquatic sciences. Marine Ecology Progress Series 446: 285-302.

Larsen TH, Williams NM, Kremen C. 2005. Extinction order and altered community structure rapidly disrupt ecosystem functioning. Ecology Letters 8: 538-547.

Levin LA, Boesch DF, Covich A, Dahm C, Erséus C, Ewel KC, Kneib RT, Moldenke A, Palmer MA, Snelgrove P, Strayer D, Weslawski JM. 2001. The Function of Marine Critical Transition Zones and the Importance of Sediment Biodiversity. Ecosystems 4: 430-451.

Link H, Chaillou G, Forest A, Piepenburg D, Archambault P. 2013. Multivariate benthic ecosystem functioning in the Arctic - benthic fluxes explained by environmental parameters in the southeastern Beaufort Sea. Biogeosciences 10: 5911-5929.

Lohrer AM, Thrush SF, Hewitt JE, Berkenbusch K, Ahrens M, Cummings VJ. 2004. Terrestrially derived sediment: response of marine macrobenthic communities to thin terrigenous deposits. Marine Ecology Progress Series 273: 121-138.

Lohrer AM, Thrush SF, Hewitt JE, Kraan C. 2015. The up-scaling of ecosystem functions in a heterogeneous world. Sci. Rep. 5.

McGinnis DF, Sommer S, Lorke A, Glud RN, Linke P. 2014. Quantifying tidally driven benthic oxygen exchange across permeable sediments: An aquatic eddy correlation study. Journal of Geophysical Research: Oceans 119: 6918-6932.

Meadows PS, Meadows A, Murray JMH. 2012. Biological modifiers of marine benthic seascapes: Their role as ecosystem engineers. Geomorphology 157: 31-48.

Mermillod-Blondin F, Rosenberg R. 2006. Ecosystem engineering: the impact of bioturbation on biogeochemical processes in marine and freshwater benthic habitats. Aquatic Sciences 68: 434-442.

Mogg AOM, Attard KM, Stahl H, Brand T, Turnewitsch R, Sayer MDJ. 2017. The influence of coring method on the preservation of sedimentary and biogeochemical features when sampling soft- 
bottom, shallow coastal environments. Limnology and Oceanography: Methods doi: 10.1002/lom3.10211.

Moodley L, Middelburg JJ, Soetaert K, Boschker HTS, Herman PMJ, Heip CHR. 2005. Similar rapid response to phytodetritus deposition in shallow and deep-sea sediments. Journal of Marine Research 63: 457-469.

Naeem S. 2008. Advancing realism in biodiversity research. Trends in Ecology \& Evolution 23: 414-416.

Needham HR, Pilditch CA, Lohrer AM, Thrush SF. 2011. Context-Specific Bioturbation Mediates Changes to Ecosystem Functioning. Ecosystems 14: 1096-1109.

Norkko A, Villnäs A, Norkko J, Valanko S, Pilditch C. 2013. Size matters: implications of the loss of large individuals for ecosystem function. Scientific Reports 3.

Norkko J, Gammal J, Hewitt J, Josefson A, Carstensen J, Norkko A. 2015. Seafloor Ecosystem Function Relationships: In Situ Patterns of Change Across Gradients of Increasing Hypoxic Stress. Ecosystems 18: 1424-1439.

Pearson TH, Rosenberg R. 1978. Macrobenthic succession in relation to organic enrichment and pollution of the marine environment. Oceanography and Marine Biology - an Annual Review 16: 229 311.

Poage MA, Barrett JE, Virginia RA, Wall DH. 2008. The Influence of Soil Geochemistry on Nematode Distribution, Mcmurdo Dry Valleys, Antarctica. Arctic, Antarctic, and Alpine Research 40: 119-128.

Pratt DR, Lohrer AM, Pilditch CA, Thrush SF. 2014. Changes in Ecosystem Function Across Sedimentary Gradients in Estuaries. Ecosystems 17: 182-194.

Reise K. 2002. Sediment mediated species interactions in coastal waters. Journal of Sea Research 48: 127141.

Reiss J, Bridle JR, Montoya JM, Woodward G. 2009. Emerging horizons in biodiversity and ecosystem functioning research. Trends in Ecology \& Evolution 24: 505-514.

Riisgård HU, Kamermans P. 2001. Switching Between Deposit and Suspension Feeding in Coastal Zoobenthos. Reise K editor. Ecological Comparisons of Sedimentary Shores. Berlin, Heidelberg: Springer Berlin Heidelberg, p73-101.

Sereda JM, Hudson JJ. 2011. Empirical models for predicting the excretion of nutrients ( $\mathrm{N}$ and $\mathrm{P}$ ) by aquatic metazoans: taxonomic differences in rates and element ratios. Freshwater Biology 56: 250263.

Snelgrove PVR, Thrush SF, Wall DH, Norkko A. 2014. Real world biodiversity-ecosystem functioning: a seafloor perspective. Trends in Ecology \& Evolution 29: 398-405.

Solan M, Cardinale BJ, Downing AL, Engelhardt KAM, Ruesink JL, Srivastava DS. 2004. Extinction and ecosystem function in the marine benthos. Science 306: 1177-1180.

Solan M, Godbold JA, Symstad A, Flynn DFB, Bunker D. 2009. Biodiversity-ecosystem function research and biodiversity futures: Early bird catches the worm or a day late and a dollar short? Naeem S, Bunker DE, Hector A, Loreau M, Perrings C, editors. Biodiversity and human impacts: ecological and societal implications. Oxford University Press, Oxford.

Stachowicz JJ, Bruno JF, Duffy JE. 2007. Understanding the effects of marine biodiversity on communities and ecosystems. Annual Review of Ecology Evolution and Systematics, p739-766.

Sylvain ZA, Wall DH, Cherwin KL, Peters DPC, Reichmann LG, Sala OE. 2014. Soil animal responses to moisture availability are largely scale, not ecosystem dependent: insight from a cross-site study. Global Change Biology 20: 2631-2643.

Thrush SF, Hewitt JE, Gibbs M, Lundquist C, Norkko A. 2006. Functional role of large organisms in intertidal communities: Community effects and ecosystem function. Ecosystems 9: 10291040.

Thrush SF, Hewitt JE, Kraan C, Lohrer AM, Pilditch CA, Douglas E. 2017. Changes in the location of biodiversity-ecosystem function hot spots across the seafloor landscape with increasing sediment nutrient loading. Proceedings of the Royal Society B: Biological Sciences 284.

Thrush SF, Hewitt JE, Norkko A, Nicholls PE, Funnell GA, Ellis JI. 2003. Habitat change in estuaries: predicting broad-scale responses of intertidal macrofauna to sediment mud content. Marine Ecology Progress Series 263: 101-112. 
Urban-Malinga B, Drgas A, Gromisz S, Barnes N. 2014. Species-specific effect of macrobenthic assemblages on meiobenthos and nematode community structure in shallow sandy sediments. Marine Biology 161: 195-212.

Vanni MJ, McIntyre PB. 2016. Predicting nutrient excretion of aquatic animals with metabolic ecology and ecological stoichiometry: a global synthesis. Ecology 97: 3460-3471.

Villnäs A, Hewitt J, Snickars M, Westerbom M, Norkko A. 2017. Template for using biological trait groupings when exploring large-scale variation in seafloor multifunctionality. Ecological Applications doi: 10.1002/eap.1630.

Villnäs A, Norkko J, Hietanen S, Josefson AB, Lukkari K, Norkko A. 2013. The role of recurrent disturbances for ecosystem multifunctionality. Ecology 94: 2275-2287.

Virginia RA, Wall DH. 1999. How Soils Structure Communities in the Antarctic Dry Valleys. Bioscience 49: 973-983.

Vitousek PM., Mooney HA, Lubchenco J, Melillo JM. 1997. Human domination of Earth's ecosystems. Science 277: 494-499.

Wall DH, Bradford MA, St. John MG, Trofymow JA, Behan-Pelletier V, Bignell DE, Dangerfield JM, Parton WJ, Rusek J, Voigt W, Wolters V, Gardel HZ, Ayuke FO, Bashford R, Beljakova OI, Bohlen PJ, Brauman A, Flemming S, Henschel JR, Johnson DL, Jones TH, Kovarova M, Kranabetter JM, Kutny LES, Lin K-C, Maryati M, Masse D, Pokarzhevskii A, Rahman H, SabarÁ MG, Salamon J-A, Swift MJ, Varela A, Vasconcelos HL, White DON, Zou X. 2008. Global decomposition experiment shows soil animal impacts on decomposition are climatedependent. Global Change Biology 14: 2661-2677.

Wentworth CK. 1922. A scale of grade and class terms for clastic sediments. The Journal of Geology 30: 377-392. 
Table 1. Environmental and habitat characteristics, min-max (mean), within the sediment types (coarse $\mathrm{n}=$ 51 , medium $\mathrm{n}=14$, fine sediments $\mathrm{n}=19$ ).

\begin{tabular}{llll}
\hline & Coarse sediment & Medium sediment & Fine sediment \\
\hline D50 $(\mu \mathrm{m})$ & $198-845(400)$ & $116-168(150)$ & $21-79(40)$ \\
Depth $(\mathrm{m})$ & $1.7-3.8(2.8)$ & $2.5-3.9(3.0)$ & $2.2-2.7(2.4)$ \\
Temperature $\left({ }^{\circ} \mathrm{C}\right)$ & $14-23(17)$ & $15-22(20)$ & $14-22(17)$ \\
Oxygen conc. at bottom $\left(\mathrm{mg} \mathrm{l}^{-1}\right)$ & $7.0-10.0(9)$ & $8.6-10.2(9)$ & $8.2-10.2(9)$ \\
Salinity & $5.1-5.7(5.4)$ & $5.1-5.6(5.3)$ & $5.1-5.6(5.3)$ \\
OM $(\%)$ & $0.2-2 \%(0.7 \%)$ & $0.5-3 \%(0.8 \%)$ & $3-17 \%(7 \%)$ \\
Chl ( $\left(\mu \mathrm{g} \mathrm{g}^{-1}\right.$ sediment $)$ & $3-41(18)$ & $10-21(15)$ & $14-138(40)$ \\
Total abundance $\left(\mathrm{ind} . \mathrm{m}^{-2}\right)$ & $1600-25000(11000)^{*}$ & $1300-30000(6700)$ & $0-9400(3600)$ \\
Total biomass $\left(\mathrm{g}\right.$ wwt $\left.\mathrm{m}^{-2}\right)$ & $12-590(131)^{*}$ & $1.5-350(103)$ & $0-170(35)$ \\
Species richness & $4-12(7)$ & $1-9(5)$ & $0-6(4)$ \\
Vegetation cover $(\%)$ & $0-80 \%(23 \%)$ & $0.5-55 \%(18 \%)$ & $0-15 \%(3 \%)$ \\
Microphytobenthos cover $(\%)$ & - & - & $0-90 \%(51 \%)$ \\
Vegetation species cover $(\%)$ & & & \\
Zostera marina & $0-80 \%(10 \%)$ & - & - \\
Zannichellia lacustris & $0-70 \%(3 \%)$ & $0-1 \%(0.3 \%)$ & - \\
Stuckenia pectinata & $0-30 \%(1 \%)$ & $0-30 \%(6 \%)$ & $0-15 \%(1 \%)$ \\
Potamogeton perfoliatus & $0-40 \%(7 \%)$ & $0-25 \%(8 \%)$ & $0-10 \%(1 \%)$ \\
Myriophyllum spp. & $0-15 \%(1 \%)$ & $0-22 \%(3 \%)$ & $0-2 \%(0.3 \%)$ \\
\hline
\end{tabular}

*Including the stochastically distributed bivalve Mya arenaria, the values for abundance are 1800-25000 (11000) and for biomass 12-3000 (345). 
Table 2. Distance-based Linear Model results between environmental and biological predictors and the combined solute fluxes as a measure of ecosystem functioning for i) all cores $(n=85)$, ii) coarse sediments $(\mathrm{n}=51)$, iii) medium sediments $(\mathrm{n}=14)$ and iv) fine sediments $(\mathrm{n}=19)$. Marginal tests indicate the proportion of variation explained by predictors when fitted individually, while the sequential tests indicate the proportion of variation explained by the predictors when fitted sequentially.

Marginal test Sequential test

i) All cores

Biomass H. diversicolor

Temperature

Roots

$\mathrm{OM}$

Vegetation cover

Biomass of small C. glaucum

Abundance of large $M$. balthica

Drifting algae

ii) Coarse sediment

Roots

Biomass H. diversicolor

Depth

Vegetation cover

Abundance of small M. balthica

Biomass Marenzelleria spp.
$0.205^{* * *}$

$0.049 *$

$0.056^{*}$

$0.038^{*}$

0.020

0.019

0.017

0.011
$0.205^{* * *}$

$0.059 * *$

$0.046 * *$

$0.046^{* *}$

$0.031 *$

$0.023^{*}$

$0.021^{*}$

0.020
Cumulative proportion explained

iii) Medium sediment

Abundance $H$. diversicolor
Abundance of small M. balthica

$0.508^{* * *}$

$0.508^{* * *}$

0.508

0.042

$0.178^{* *}$

0.686

iv) Fine sediment

$\begin{array}{llll}\text { Biomass } H \text {. diversicolor } & 0.436 * * * & 0.436^{* * *} & 0.436 \\ \text { Microphytobenthos cover } & 0.251^{* * *} & 0.251^{* * *} & 0.688 \\ \text { Biomass Hydrobiidae } & 0.075^{* *} & 0.075^{* *} & 0.762\end{array}$

*** $\mathrm{p}<0.001, * * \mathrm{p}<0.01, * \mathrm{p}<0.05$ 

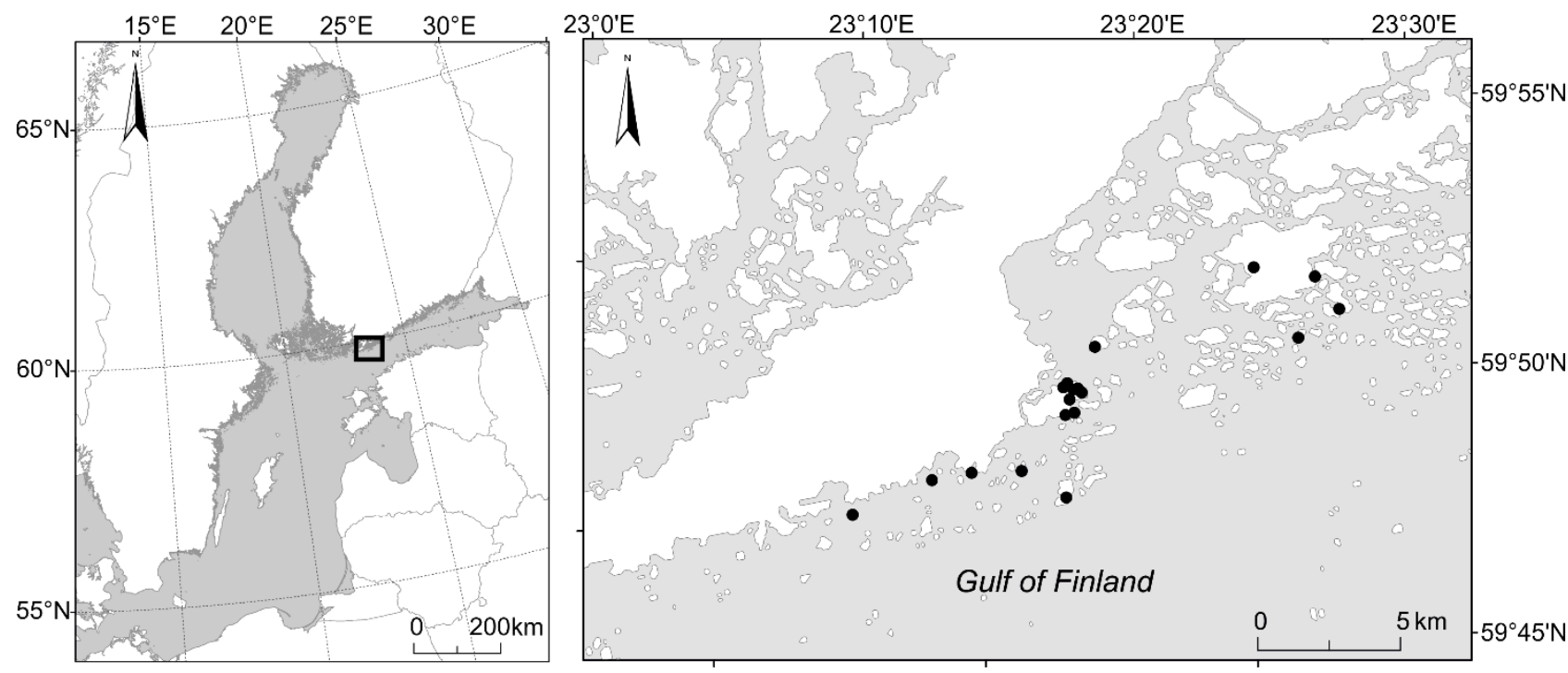

Figure 1. The 18 sampling sites in the Hanko archipelago, western Gulf of Finland (map layers: HELCOM). 


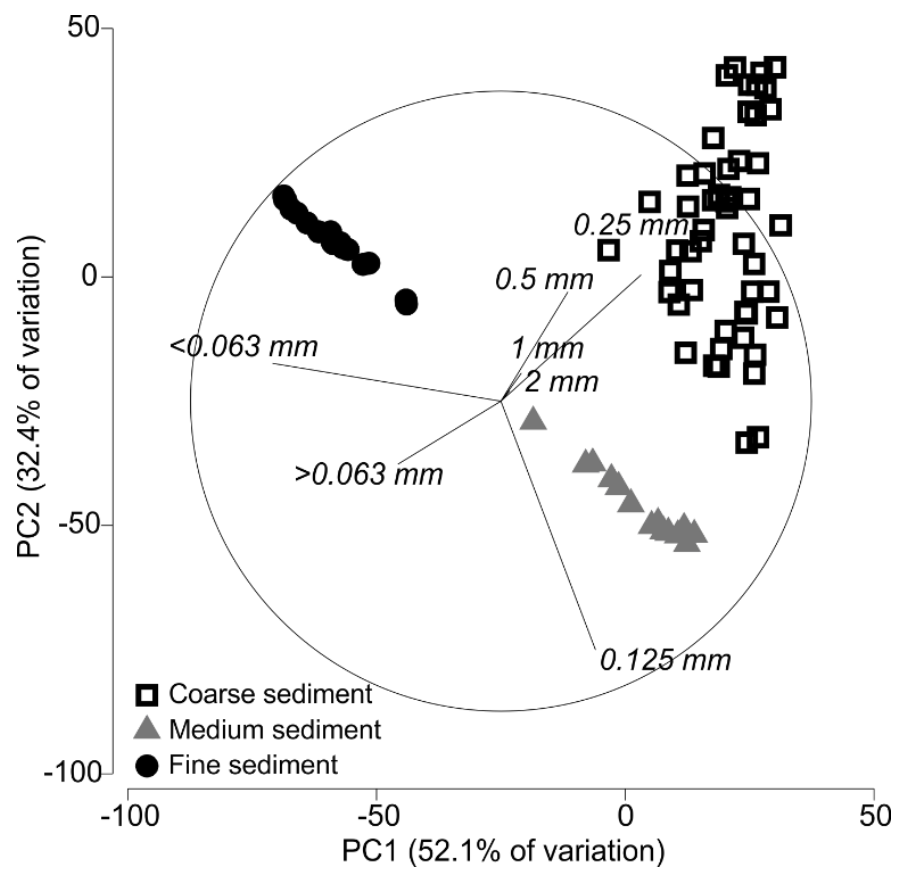

Figure 2. PCA-analysis illustrating the split into sediment types based on cluster analysis of the grain size fractions (coarse $\mathrm{n}=51$, medium $\mathrm{n}=14$ and fine sediment $\mathrm{n}=19$ ). 


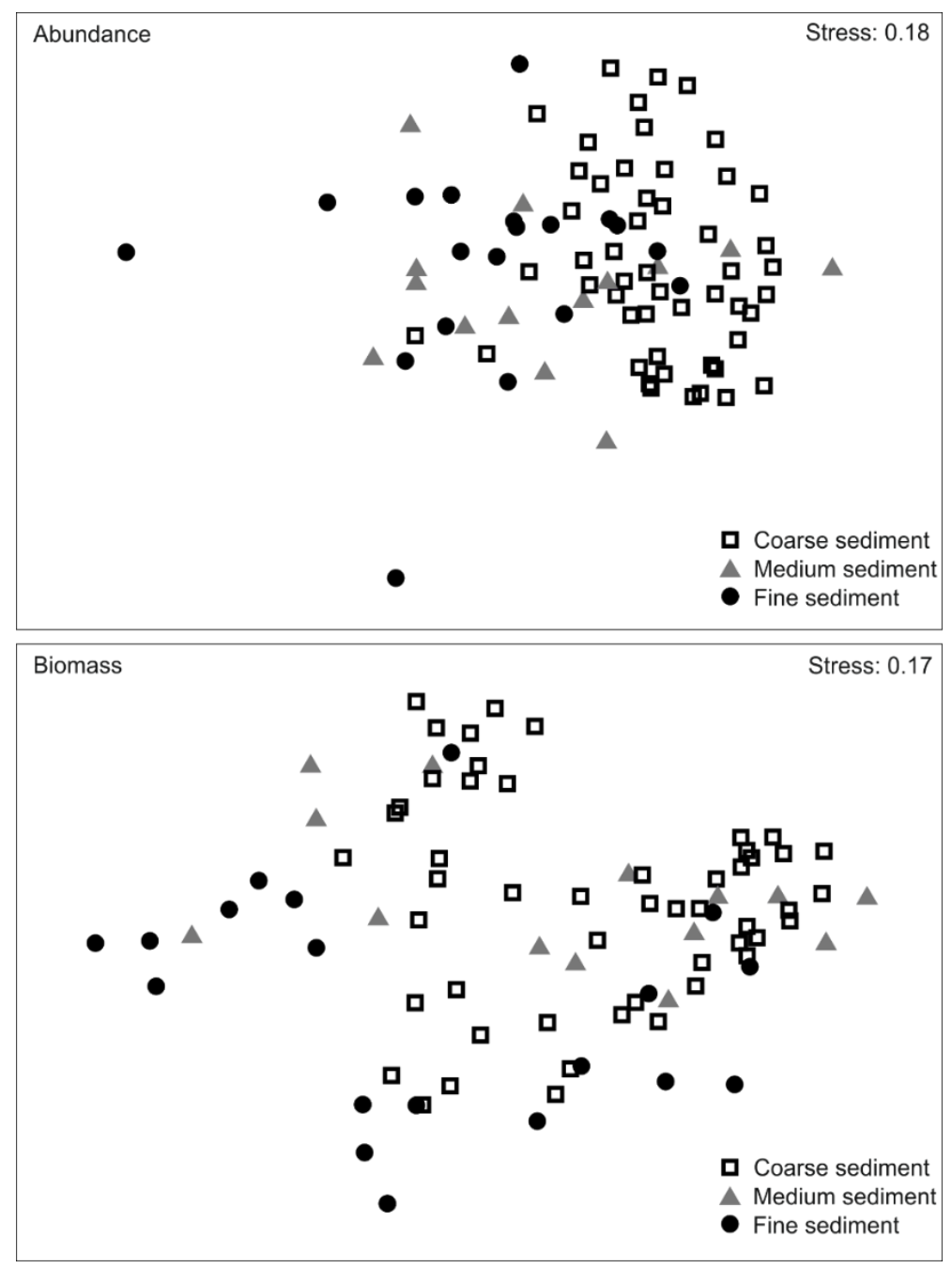

Figure 3. nMDS-plots of untransformed macrofauna community abundance and biomass (based on BrayCurtis similarity) with the different sediment types indicated. 

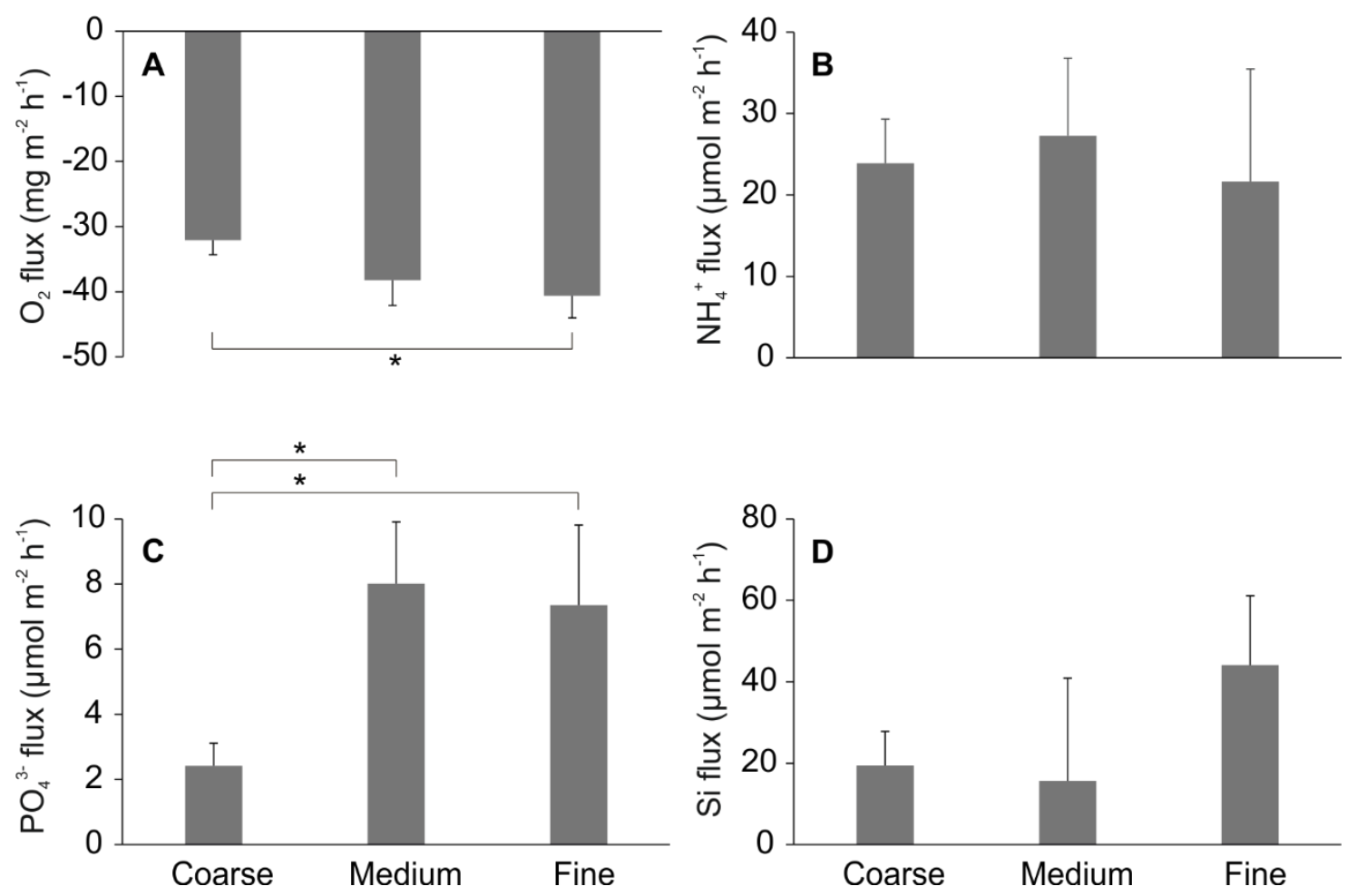

Figure 4. Mean fluxes (+SE) of A) $\left.\mathrm{O}_{2}, \mathrm{~B}\right) \mathrm{NH}_{4}{ }^{+}$, C) $\mathrm{PO}_{4}{ }^{3-}$, D) $\mathrm{Si}$ in the sediment types. All fluxes are in $\mu \mathrm{mol}$ $\mathrm{m}^{-2} \mathrm{~h}^{-1}$ except $\mathrm{O}_{2}$ in $\mathrm{mg} \mathrm{m}^{-2} \mathrm{~h}^{-1}$. The significant between-group differences (PERMANOVA) are indicated $(*$ $\mathrm{p}<0.05$ ). 


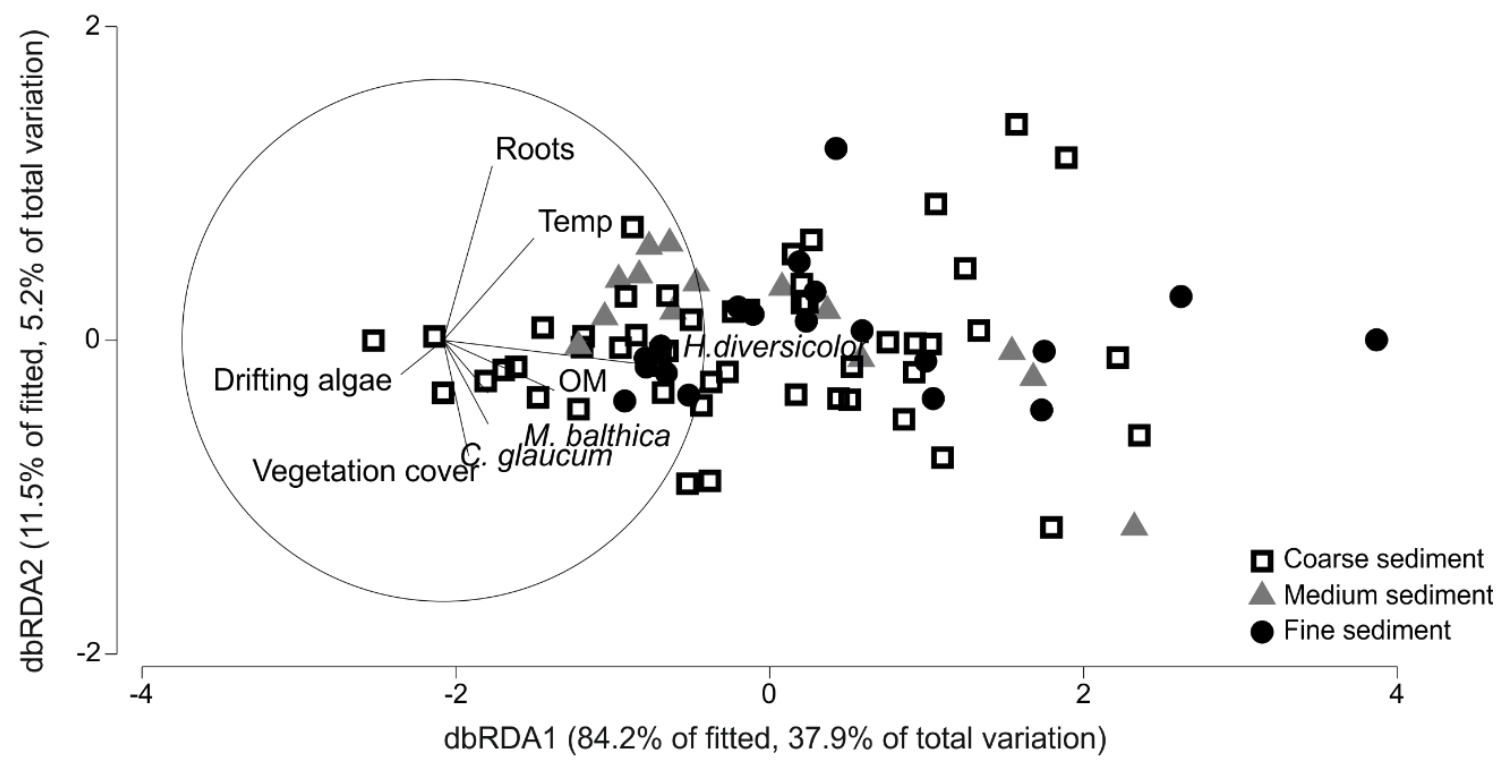

Figure 5. Illustration by dbRDA of the relationships between the modeled predictors and the multivariate solute fluxes from the DistLM-analysis of all cores $(n=85)$. The closer the samples are together, the more similar are their fluxes and the vectors indicate the direction and importance of the predictors for the solute fluxes on the two axes. The different symbols indicate to which sediment type the cores belong. 
Supplementary data

Title: Environmental context mediates biodiversity-ecosystem functioning relationships in coastal soft-sediment habitats

Authors: Gammal J., Järnström M., Bernard G., Norkko J. and Norkko A.

Appendix 1. Average $( \pm \mathrm{SD})$ abundance (ind. $\left.\mathrm{m}^{-2}\right)$ at the sampling sites of the species/taxa present $(\mathrm{n}=5$ for all sites, except 1,6 and 11 , were $\mathrm{n}=4$ and site 16 , where $\mathrm{n}=3$ ).

Taxa included in Others are Mya arenaria, Chironomidae, Mytilus edulis, Theodoxus fluviatilis, Bathyporeia pilosa, Corophium volutator and Limapontia capitata. Taxonomic class: B Bivalvia, P Polychaeta, G Gastropoda, O Subclass Oligochaeta, N Phylum Nemertea.

\begin{tabular}{|c|c|c|c|c|c|c|c|c|c|c|c|}
\hline Site & $\begin{array}{l}\text { Macoma } \\
\text { balthica } \\
\mathrm{B} \\
\end{array}$ & $\begin{array}{l}\text { Cerastoderma } \\
\text { glaucum } \\
\mathrm{B} \\
\end{array}$ & $\begin{array}{l}\text { Marenzelleria } \\
\text { spp. } \\
\mathrm{P} \\
\end{array}$ & $\begin{array}{l}\text { Hediste } \\
\text { diversicolor } \\
\mathrm{P}\end{array}$ & $\begin{array}{l}\text { Pygospio } \\
\text { elegans } \\
\mathrm{P} \\
\end{array}$ & $\begin{array}{l}\text { Manayunkia } \\
\text { aestuarina } \\
\mathrm{P} \\
\end{array}$ & $\begin{array}{l}\text { Hydrobiidae } \\
\text { G }\end{array}$ & $\begin{array}{l}\text { Olighochaeta } \\
\mathrm{O}\end{array}$ & $\begin{array}{l}\text { Cyanophthalma } \\
\text { obscura } \\
\mathrm{N}\end{array}$ & Others & Total abundance \\
\hline 1 & $496 \pm 400$ & $45 \pm 90$ & $496 \pm 308$ & $45 \pm 90$ & $0 \pm 0$ & $181 \pm 147$ & $677 \pm 271$ & $45 \pm 90$ & $45 \pm 90$ & $45 \pm 90$ & $2076 \pm 617$ \\
\hline 2 & $469 \pm 328$ & $830 \pm 658$ & $614 \pm 374$ & $397 \pm 391$ & $144 \pm 81$ & $0 \pm 0$ & $6498 \pm 2174$ & $830 \pm 520$ & $144 \pm 235$ & $253 \pm 206$ & $10180 \pm 2383$ \\
\hline 3 & $1408 \pm 1802$ & $325 \pm 297$ & $469 \pm 328$ & $144 \pm 151$ & $0 \pm 0$ & $217 \pm 323$ & $2635 \pm 871$ & $253 \pm 242$ & $0 \pm 0$ & $144 \pm 235$ & $5596 \pm 3039$ \\
\hline 4 & $2491 \pm 1108$ & $0 \pm 0$ & $36 \pm 81$ & $72 \pm 99$ & $0 \pm 0$ & $181 \pm 313$ & $1913 \pm 977$ & $866 \pm 467$ & $0 \pm 0$ & $72 \pm 99$ & $5632 \pm 2281$ \\
\hline 5 & $3791 \pm 1977$ & $397 \pm 412$ & $433 \pm 374$ & $686 \pm 412$ & $1661 \pm 2149$ & $325 \pm 630$ & $2888 \pm 3981$ & $4765 \pm 2278$ & $578 \pm 590$ & $253 \pm 352$ & $15776 \pm 8401$ \\
\hline 6 & $2166 \pm 2211$ & $406 \pm 697$ & $1038 \pm 713$ & $271 \pm 104$ & $0 \pm 0$ & $90 \pm 181$ & $6137 \pm 4009$ & $993 \pm 699$ & $316 \pm 173$ & $90 \pm 104$ & $11507 \pm 8188$ \\
\hline 7 & $1841 \pm 449$ & $866 \pm 841$ & $794 \pm 302$ & $217 \pm 151$ & $866 \pm 604$ & $0 \pm 0$ & $1011 \pm 960$ & $1155 \pm 1459$ & $325 \pm 449$ & $397 \pm 323$ & $7473 \pm 926$ \\
\hline 8 & $975 \pm 374$ & $469 \pm 302$ & $686 \pm 247$ & $0 \pm 0$ & $325 \pm 391$ & $0 \pm 0$ & $10578 \pm 2220$ & $578 \pm 656$ & $433 \pm 328$ & $36 \pm 81$ & $14079 \pm 2740$ \\
\hline 9 & $614 \pm 302$ & $72 \pm 99$ & $144 \pm 151$ & $181 \pm 181$ & $0 \pm 0$ & $0 \pm 0$ & $1083 \pm 972$ & $0 \pm 0$ & $181 \pm 313$ & $36 \pm 81$ & $2310 \pm 1383$ \\
\hline 10 & $6967 \pm 3182$ & $253 \pm 374$ & $325 \pm 235$ & $181 \pm 221$ & $36 \pm 81$ & $36 \pm 81$ & $3032 \pm 2636$ & $1119 \pm 562$ & $108 \pm 242$ & $181 \pm 313$ & $12238 \pm 6032$ \\
\hline 11 & $1083 \pm 1113$ & $45 \pm 90$ & $1489 \pm 948$ & $406 \pm 90$ & $1715 \pm 1088$ & $226 \pm 173$ & $1264 \pm 780$ & $2031 \pm 1056$ & $135 \pm 90$ & $0 \pm 0$ & $8393 \pm 2755$ \\
\hline 12 & $1625 \pm 338$ & $505 \pm 198$ & $722 \pm 383$ & $722 \pm 404$ & $1119 \pm 811$ & $433 \pm 206$ & $3971 \pm 3333$ & $2130 \pm 501$ & $144 \pm 151$ & $108 \pm 242$ & $11480 \pm 4751$ \\
\hline 13 & $3430 \pm 2588$ & $433 \pm 471$ & $542 \pm 460$ & $361 \pm 423$ & $2419 \pm 1739$ & $36 \pm 81$ & $2852 \pm 2423$ & $2094 \pm 1852$ & $217 \pm 297$ & $144 \pm 198$ & $12527 \pm 8324$ \\
\hline 14 & $1336 \pm 813$ & $0 \pm 0$ & $217 \pm 151$ & $1191 \pm 646$ & $0 \pm 0$ & $144 \pm 198$ & $1949 \pm 1784$ & $939 \pm 1048$ & $144 \pm 235$ & $217 \pm 198$ & $6137 \pm 3170$ \\
\hline 15 & $939 \pm 1108$ & $397 \pm 888$ & $0 \pm 0$ & $72 \pm 99$ & $0 \pm 0$ & $144 \pm 235$ & $253 \pm 352$ & $0 \pm 0$ & $72 \pm 161$ & $36 \pm 81$ & $1913 \pm 1324$ \\
\hline 16 & $2467 \pm 1677$ & $120 \pm 202$ & $602 \pm 276$ & $181 \pm 181$ & $0 \pm 0$ & $60 \pm 104$ & $4813 \pm 1355$ & $181 \pm 181$ & $0 \pm 0$ & $0 \pm 0$ & $8424 \pm 1160$ \\
\hline 17 & $5523 \pm 4525$ & $108 \pm 161$ & $289 \pm 302$ & $289 \pm 206$ & $36 \pm 81$ & $397 \pm 692$ & $4621 \pm 3548$ & $1877 \pm 2172$ & $72 \pm 99$ & $108 \pm 242$ & $13321 \pm 10583$ \\
\hline 18 & $2166 \pm 1915$ & $72 \pm 99$ & $72 \pm 161$ & $253 \pm 206$ & $0 \pm 0$ & $0 \pm 0$ & $1733 \pm 1390$ & $0 \pm 0$ & $0 \pm 0$ & $72 \pm 99$ & $4368 \pm 3120$ \\
\hline
\end{tabular}


Appendix 2. Average $( \pm \mathrm{SD})$ biomass $\left(\mathrm{g} \mathrm{wwt} \mathrm{m}^{-2}\right)$ at the sampling sites of the species/taxa present $(\mathrm{n}=5$ for all sites, except 1,6 and 11 , were $\mathrm{n}=4$ and site 16 , where $\mathrm{n}=3$ ).

Taxa included in Others are Mya arenaria, Chironomidae, Mytilus edulis, Theodoxus fluviatilis, Bathyporeia pilosa, Corophium volutator and Limapontia capitata. Taxonomic class: B Bivalvia, P Polychaeta, G Gastropoda, O Subclass Oligochaeta, N Phylum Nemertea.

\begin{tabular}{|c|c|c|c|c|c|c|c|c|c|c|c|}
\hline Site & $\begin{array}{l}\text { Macoma } \\
\text { balthica } \\
\mathrm{B}\end{array}$ & $\begin{array}{l}\text { Cerastoderma } \\
\text { glaucum } \\
\mathrm{B}\end{array}$ & $\begin{array}{l}\text { Marenzelleria } \\
\text { spp. } \\
\mathrm{P}\end{array}$ & $\begin{array}{l}\text { Hediste } \\
\text { diversicolor } \\
\mathrm{P}\end{array}$ & $\begin{array}{l}\text { Pygospio } \\
\text { elegans } \\
\mathrm{P} \\
\end{array}$ & $\begin{array}{l}\text { Manayunkia } \\
\text { aestuarina } \\
\mathrm{P}\end{array}$ & $\begin{array}{l}\text { Hydrobiidae } \\
\text { G }\end{array}$ & $\begin{array}{l}\text { Olighochaeta } \\
\text { O }\end{array}$ & $\begin{array}{l}\text { Cyanophthalma } \\
\text { obscura } \\
\mathrm{N}\end{array}$ & Others & $\begin{array}{l}\text { Total } \\
\text { biomass }\end{array}$ \\
\hline 1 & $91 \pm 106$ & $<0.1 \pm<0.1$ & $4 \pm 4$ & $0.5 \pm 1$ & $0 \pm 0$ & $0 \pm 0$ & $2 \pm 0.4$ & $0 \pm 0$ & $0 \pm 0$ & $0 \pm 0$ & $97 \pm 106$ \\
\hline 2 & $47 \pm 58$ & $114 \pm 254$ & $16 \pm 21$ & $4 \pm 5$ & $0 \pm 0$ & $0 \pm 0$ & $14 \pm 10$ & $0.3 \pm 0.5$ & $0.1 \pm 0.2$ & $358 \pm 795$ & $554 \pm 733$ \\
\hline 3 & $41 \pm 48$ & $8 \pm 18$ & $11 \pm 8$ & $3 \pm 5$ & $<0.1 \pm<0.1$ & $0.4 \pm 0.8$ & $8 \pm 3$ & $<0.1 \pm<0.1$ & $0 \pm 0$ & $<0.1 \pm 0.1$ & $71 \pm 49$ \\
\hline 4 & $21 \pm 28$ & $0 \pm 0$ & $0.1 \pm 0.3$ & $30 \pm 47$ & $0 \pm 0$ & $0 \pm 0$ & $5 \pm 2$ & $0.1 \pm 0.2$ & $0 \pm 0$ & $<0.1 \pm 0.1$ & $56 \pm 68$ \\
\hline 5 & $60 \pm 83$ & $22 \pm 49$ & $7 \pm 8$ & $19 \pm 18$ & $1 \pm 1$ & $0 \pm 0$ & $9 \pm 11$ & $1 \pm 0.7$ & $0.9 \pm 0.8$ & $0.2 \pm 0.4$ & $119 \pm 98$ \\
\hline 6 & $151 \pm 152$ & $20 \pm 40$ & $28 \pm 22$ & $9 \pm 7$ & $0 \pm 0$ & $0 \pm 0$ & $16 \pm 9$ & $0.3 \pm 0.4$ & $0.1 \pm<0.1$ & $5 \pm 10$ & $231 \pm 198$ \\
\hline 7 & $101 \pm 117$ & $0.6 \pm 0.6$ & $6 \pm 8$ & $7 \pm 14$ & $0.2 \pm 0.2$ & $0 \pm 0$ & $1 \pm 1$ & $0.1 \pm 0.3$ & $<0.1 \pm 0.2$ & $0.4 \pm 0.5$ & $117 \pm 116$ \\
\hline 8 & $20 \pm 27$ & $2 \pm 1$ & $11 \pm 11$ & $0 \pm 0$ & $<0.1 \pm<0.1$ & $0 \pm 0$ & $14 \pm 4$ & $0.3 \pm 0.4$ & $0.4 \pm 0.5$ & $0 \pm 0$ & $48 \pm 26$ \\
\hline 9 & $28 \pm 38$ & $0 \pm 0$ & $2 \pm 4$ & $6 \pm 8$ & $0 \pm 0$ & $0 \pm 0$ & $2 \pm 2$ & $0 \pm 0$ & $0.1 \pm 0.2$ & $0 \pm 0$ & $37 \pm 37$ \\
\hline 10 & $88 \pm 107$ & $2 \pm 2$ & $3 \pm 3$ & $3 \pm 4$ & $0 \pm 0$ & $0 \pm 0$ & $7 \pm 7$ & $0.3 \pm 0.4$ & $<0.1 \pm 0.2$ & $405 \pm 906$ & $509 \pm 1020$ \\
\hline 11 & $79 \pm 96$ & $0.3 \pm 0.6$ & $28 \pm 17$ & $5 \pm 5$ & $0.4 \pm 0.2$ & $0 \pm 0$ & $6 \pm 3$ & $0.6 \pm 0.4$ & $0.1 \pm 0.1$ & $0 \pm 0$ & $119 \pm 103$ \\
\hline 12 & $106 \pm 89$ & $23 \pm 35$ & $9 \pm 10$ & $39 \pm 37$ & $0.2 \pm 0.1$ & $<0.1 \pm<0.1$ & $8 \pm 8$ & $1 \pm 1$ & $0.2 \pm 0.3$ & $0.3 \pm 0.6$ & $187 \pm 29$ \\
\hline 13 & $83 \pm 85$ & $34 \pm 75$ & $11 \pm 16$ & $9 \pm 10$ & $0.3 \pm 0.5$ & $0 \pm 0$ & $6 \pm 5$ & $0.7 \pm 0.8$ & $0.1 \pm 0.3$ & $260 \pm 424$ & $403 \pm 455$ \\
\hline 14 & $31 \pm 68$ & $0 \pm 0$ & $16 \pm 16$ & $8 \pm 6$ & $0 \pm 0$ & $0 \pm 0$ & $5 \pm 4$ & $<0.1 \pm 0.2$ & $<0.1 \pm 0.1$ & $1157 \pm 1585$ & $1217 \pm 1569$ \\
\hline 15 & $0.3 \pm 0.3$ & $0.2 \pm 0.5$ & $0 \pm 0$ & $6 \pm 13$ & $0 \pm 0$ & $0 \pm<0.1$ & $0.5 \pm 0.9$ & $0 \pm 0$ & $<0.1 \pm 0.2$ & $0.2 \pm 0.4$ & $7 \pm 13$ \\
\hline 16 & $80 \pm 137$ & $1 \pm 2$ & $9 \pm 6$ & $0.3 \pm 0$ & $0 \pm 0$ & $0 \pm 0$ & $6 \pm 4$ & $<0.1 \pm<0.1$ & $0 \pm 0$ & $0 \pm 0$ & $96 \pm 128$ \\
\hline 17 & $151 \pm 127$ & $1 \pm 2$ & $8 \pm 11$ & $13 \pm 16$ & $<0.1 \pm<0.1$ & $<0.1 \pm 0.1$ & $7 \pm 5$ & $0.4 \pm 0.5$ & $<0.1 \pm<0.1$ & $<0.1 \pm<0.1$ & $180 \pm 120$ \\
\hline 18 & $16 \pm 22$ & $0.1 \pm 0.3$ & $5 \pm 11$ & $9 \pm 12$ & $0 \pm 0$ & $0 \pm 0$ & $2 \pm 2$ & $0 \pm 0$ & $0 \pm 0$ & $0 \pm 0$ & $32 \pm 24$ \\
\hline
\end{tabular}


Appendix 3. PERMANOVA table showing differences in abundance and biomass between the three sediment types (coarse, medium and fine sediments).

\begin{tabular}{llllll}
\hline Abundance & df & SS & MS & Pseudo-F & P(perm) \\
\hline Sediment type & 2 & 22905 & 11452 & 7.2405 & 0.0001 \\
Residuals & 81 & $1.2812 \mathrm{E}+05$ & 1581.7 & & \\
Total & 83 & $1.5102 \mathrm{E}+05$ & & & \\
Pair-wise test & $\mathrm{t}$ & $\mathrm{p}(\mathrm{perm})$ & & & \\
medium, coarse & 2.3858 & 0.0003 & & & \\
medium, fine & 1.0923 & 0.2987 & & Pseudo-F & $\mathrm{P}($ perm) \\
coarse, fine & 3.4585 & 0.0001 & & 3.5911 & 0.0009 \\
Biomass & $\mathrm{df}$ & $\mathrm{SS}$ & $\mathrm{MS}$ & & \\
\hline Sediment type & 2 & 19428 & 9713.9 & & \\
Residuals & 81 & $2.1911 \mathrm{E}+05$ & 2705 & & \\
Total & 83 & $2.3853 \mathrm{E}+05$ & & & \\
Pair-wise test & $\mathrm{t}$ & $\mathrm{P}(\mathrm{perm})$ & & & \\
medium, coarse & 0.97651 & 0.41 & & & \\
medium, fine & 1.6288 & 0.0246 & & & \\
coarse, fine & 2.5418 & 0.0002 & & & \\
\hline
\end{tabular}


Appendix 4. SIMPER analysis identifying the percent contribution of each species to the Bray Curtis dissimilarity of untransformed community abundance between the sediment types (coarse, medium and fine sediments).

Coarse - Medium

Average dissimilarity $=61.18$

\begin{tabular}{llll}
\hline & \multicolumn{2}{l}{ Average abundance } & \\
\cline { 2 - 3 } Species & Coarse & Medium & Contribution \% \\
\hline Hydrobiidae & 4169.31 & 2462.60 & 33.49 \\
M. balthica & 2431.51 & 2552.86 & 24.37 \\
Oligochaeta & 1599.77 & 683.34 & 15.85 \\
P. elegans & 743.26 & 12.89 & 7.06 \\
Marenzelleria spp. & 654.77 & 361.01 & 5.28 \\
H. diversicolor & 435.34 & 154.72 & 4.63 \\
C. glaucum & 410.56 & 167.61 & 4.21 \\
M. aestuarina & 127.42 & 257.86 & 2.58 \\
C. obscura & 244.21 & 25.79 & 2.52 \\
\hline
\end{tabular}

Coarse - Fine

Average dissimilarity $=66.53$

\begin{tabular}{llll}
\hline & \multicolumn{2}{l}{ Average abundance } & \\
\cline { 2 - 3 } Species & Coarse & Fine & Contribution \% \\
\hline Hydrobiidae & 4169.31 & 1301.54 & 34.32 \\
M. balthica & 2431.51 & 1577.04 & 21.14 \\
Oligochaeta & 1599.77 & 228.01 & 16.01 \\
P. elegans & 743.26 & 0.00 & 7.23 \\
Marenzelleria spp. & 654.77 & 66.50 & 6.86 \\
C. glaucum & 410.56 & 142.50 & 5.07 \\
H. diversicolor & 435.34 & 152.00 & 4.61 \\
C. obscura & 244.21 & 66.50 & 2.90 \\
M. aestuarina & 127.42 & 85.50 & 1.87 \\
\hline
\end{tabular}

Medium - Fine

Average dissimilarity $=59.86$

\begin{tabular}{llll}
\hline & \multicolumn{2}{l}{ Average abundance } & \\
\cline { 2 - 3 } Species & Medium & Fine & Contribution \% \\
\hline M. balthica & 2552.86 & 1577.04 & 35.10 \\
Hydrobiidae & 2462.60 & 1301.54 & 31.79 \\
Oligochaeta & 683.34 & 228.01 & 8.50 \\
Marenzelleria spp. & 361.01 & 66.50 & 8.33 \\
C. glaucum & 167.61 & 142.50 & 5.68 \\
M. aestuarina & 257.86 & 85.50 & 4.47 \\
H. diversicolor & 154.72 & 152.00 & 3.80 \\
C. obscura & 25.79 & 66.50 & 2.22 \\
P. elegans & 12.89 & 0.00 & 0.11 \\
\hline
\end{tabular}


Appendix 5. SIMPER analysis identifying the percent contribution of each species to the Bray Curtis dissimilarity of untransformed community biomass between the sediment types (coarse, medium and fine sediments).

Coarse - Medium

Average dissimilarity $=70.10$

\begin{tabular}{llll}
\hline & \multicolumn{2}{l}{ Average biomass } & \\
\cline { 2 - 3 } Species & Coarse & Medium & Contribution \% \\
\hline M. balthica & 78.08 & 82.23 & 58.69 \\
Marenzelleria spp. & 12.99 & 6.16 & 12.76 \\
H. diversicolor & 9.76 & 5.53 & 10.81 \\
C. glaucum & 21.02 & 3.31 & 9.22 \\
Hydrobiidae & 8.45 & 5.70 & 7.42 \\
Oligochaeta & 0.46 & 0.11 & 0.50 \\
C. obscura & 0.21 & 0.00 & 0.23 \\
M. aestuarina & 0.00 & 0.15 & 0.22 \\
P. elegans & 0.22 & 0.00 & 0.16 \\
\hline
\end{tabular}

Coarse - Fine

Average dissimilarity $=80.69$

\begin{tabular}{llll}
\hline & \multicolumn{2}{l}{ Average biomass } & \\
\cline { 2 - 3 } Species & Coarse & Fine & Contribution \% \\
\hline M. balthica & 78.08 & 17.21 & 48.82 \\
H. diversicolor & 9.76 & 13.24 & 17.13 \\
Marenzelleria spp. & 12.99 & 1.83 & 16.59 \\
Hydrobiidae & 8.45 & 2.37 & 8.99 \\
C. glaucum & 21.02 & 0.08 & 7.47 \\
Oligochaeta & 0.46 & 0.03 & 0.51 \\
C. obscura & 0.21 & 0.05 & 0.31 \\
P. elegans & 0.22 & 0.00 & 0.18 \\
M. aestuarina & 0.00 & 0.00 & 0.00 \\
\hline
\end{tabular}

Medium - Fine

Average dissimilarity $=81.84$

\begin{tabular}{llll}
\hline & \multicolumn{2}{l}{ Average biomass } & \\
\cline { 2 - 3 } Species & Medium & Fine & Contribution \% \\
\hline M. balthica & 82.23 & 17.21 & 54.96 \\
H. diversicolor & 5.53 & 13.24 & 16.88 \\
Marenzelleria spp. & 6.16 & 1.83 & 12.19 \\
Hydrobiidae & 5.70 & 2.37 & 11.68 \\
C. glaucum & 3.31 & 0.08 & 3.39 \\
M. aestuarina & 0.15 & 0.00 & 0.41 \\
Oligochaeta & 0.11 & 0.03 & 0.31 \\
C. obscura & 0.00 & 0.05 & 0.18 \\
P. elegans & 0.00 & 0.00 & 0.00 \\
\hline
\end{tabular}


Appendix 6. Fluxes at the sampling sites mean $\pm \operatorname{SD}(n=5$ for all sites, except 1,6 and 11 , were $n=4$ and site 16 , where $\mathrm{n}=3$ ), all solute fluxes in $\mu \mathrm{mol} \mathrm{m} \mathrm{m}^{-2} \mathrm{~h}^{-1}$ except $\mathrm{O}_{2}$ in $\mathrm{mg} \mathrm{m}^{-2} \mathrm{~h}^{-1}$.

\begin{tabular}{lllll}
\hline Site & \multicolumn{1}{c}{$\mathrm{NH}_{4}{ }^{+}$} & \multicolumn{1}{c}{$\mathrm{PO}_{4}{ }^{3-}$} & \multicolumn{1}{c}{$\mathrm{Si}$} & \multicolumn{1}{c}{$\mathrm{O}_{2}$} \\
\hline 1 & $29.5 \pm 30.1$ & $5.3 \pm 5.4$ & $-24.8 \pm 82.7$ & $-29.7 \pm 11.0$ \\
2 & $21.7 \pm 21.2$ & $5.1 \pm 3.9$ & $-6.0 \pm 19.5$ & $-33.6 \pm 8.1$ \\
3 & $28.3 \pm 29.8$ & $11.1 \pm 8.1$ & $10.6 \pm 40.3$ & $-42.4 \pm 15.4$ \\
4 & $72.1 \pm 107.2$ & $15.5 \pm 13.0$ & $108.8 \pm 90.9$ & $-46.6 \pm 21.9$ \\
5 & $36.7 \pm 31.8$ & $1.3 \pm 3.1$ & $72.6 \pm 39.0$ & $-35.3 \pm 11.2$ \\
6 & $91.5 \pm 69.1$ & $11.1 \pm 13.8$ & $-17.9 \pm 37.5$ & $-56.9 \pm 16.0$ \\
7 & $15.2 \pm 16.1$ & $-0.2 \pm 1.3$ & $23.0 \pm 60.4$ & $-28.7 \pm 9.1$ \\
8 & $7.0 \pm 7.1$ & $0.7 \pm 1.1$ & $0.8 \pm 17.0$ & $-30.5 \pm 4.9$ \\
9 & $7.2 \pm 19.2$ & $3.3 \pm 1.5$ & $9.3 \pm 22.9$ & $-34.8 \pm 14.5$ \\
10 & $8.4 \pm 20.0$ & $0.7 \pm 2.5$ & $-3.8 \pm 61.7$ & $-25.0 \pm 10.0$ \\
11 & $-18.5 \pm 8.1$ & $-0.3 \pm 0.7$ & $18.6 \pm 39.3$ & $-4.2 \pm 11.3$ \\
12 & $67.0 \pm 38.9$ & $3.2 \pm 1.5$ & $115.1 \pm 110.4$ & $-44.8 \pm 11.2$ \\
13 & $20.4 \pm 33.2$ & $1.1 \pm 2.6$ & $-4.8 \pm 26.0$ & $-40.5 \pm 13.4$ \\
14 & $4.5 \pm 5.4$ & $2.0 \pm 1.8$ & $6.0 \pm 6.6$ & $-23.3 \pm 8.1$ \\
15 & $-0.7 \pm 5.3$ & $7.6 \pm 14.5$ & $44.1 \pm 87.4$ & $-43.6 \pm 11.6$ \\
16 & $3.1 \pm 3.1$ & $2.7 \pm 3.2$ & $-11.1 \pm 23.6$ & $-20.7 \pm 5.9$ \\
17 & $25.7 \pm 49.8$ & $7.3 \pm 7.3$ & $54.3 \pm 136.0$ & $-46.4 \pm 12.9$ \\
18 & $3.1 \pm 7.1$ & $1.8 \pm 0.8$ & $3.5 \pm 15.4$ & $-34.0 \pm 9.1$ \\
\hline
\end{tabular}


Appendix 7. PERMANOVA table showing differences in the multivariate fluxes and the individual fluxes between the sediment types (coarse, medium and fine sediments).

\begin{tabular}{|c|c|c|c|c|c|}
\hline Multivariate fluxes & $\mathrm{df}$ & SS & MS & Pseudo-F & $\mathrm{P}($ perm $)$ \\
\hline Sediment type & 2 & 17.037 & 8.5186 & 2.1907 & 0.063 \\
\hline Residuals & 81 & 314.96 & 3.8884 & & \\
\hline Total & 83 & 332 & & & \\
\hline NH4 flux & $\mathrm{df}$ & SS & MS & Pseudo-F & $\mathrm{P}($ perm $)$ \\
\hline Sediment type & 2 & 0.13397 & 0.066985 & 0.065476 & 0.9391 \\
\hline Residuals & 81 & 82.866 & 1.023 & & \\
\hline Total & 83 & 83 & & & \\
\hline Pair-wise test & $\mathrm{t}$ & $\mathrm{P}($ perm $)$ & & & \\
\hline medium, coarse & 0.29103 & 0.7733 & & & \\
\hline medium, fine & 0.30973 & 0.7991 & & & \\
\hline coarse, fine & 0.18493 & 0.8657 & & & \\
\hline PO4 flux & $\mathrm{df}$ & SS & MS & Pseudo-F & $\mathrm{P}($ perm $)$ \\
\hline Sediment type & 2 & 10.135 & 5.0677 & 5.6335 & 0.0068 \\
\hline Residuals & 81 & 72.865 & 0.89956 & & \\
\hline Total & 83 & 83 & & & \\
\hline Pair-wise test & $\mathrm{t}$ & $\mathrm{P}($ perm $)$ & & & \\
\hline medium, coarse & 3.3901 & 0.002 & & & \\
\hline medium, fine & 0.19734 & 0.853 & & & \\
\hline coarse, fine & 2.6451 & 0.0111 & & & \\
\hline Si flux & df & SS & MS & Pseudo-F & $\mathrm{P}($ perm $)$ \\
\hline Sediment type & 2 & 1.997 & 0.99851 & 0.99847 & 0.3803 \\
\hline Residuals & 81 & 81.003 & 1 & & \\
\hline Total & 83 & 83 & & & \\
\hline Pair-wise test & $\mathrm{t}$ & $\mathrm{P}($ perm $)$ & & & \\
\hline medium, coarse & 0.18126 & 0.8588 & & & \\
\hline medium, fine & 0.97093 & 0.3505 & & & \\
\hline coarse, fine & 1.4352 & 0.151 & & & \\
\hline $\mathrm{O} 2$ flux & df & SS & MS & Pseudo-F & $\mathrm{P}($ perm $)$ \\
\hline Sediment type & 2 & 4.7708 & 2.3854 & 2.4699 & 0.09 \\
\hline Residuals & 81 & 78.229 & 0.96579 & & \\
\hline Total & 83 & 83 & & & \\
\hline Pair-wise test & $\mathrm{t}$ & $\mathrm{P}($ perm $)$ & & & \\
\hline medium, coarse & 1.3083 & 0.2008 & & & \\
\hline medium, fine & 0.45554 & 0.6578 & & & \\
\hline coarse, fine & 2.031 & 0.0485 & & & \\
\hline
\end{tabular}

Appendix 8. Bottom-water nutrient $\left(\mu \mathrm{mol}^{-1}\right)$ and oxygen $\left(\mathrm{mg} \mathrm{l}^{-1}\right)$ concentrations in the sediment types, mean $\pm \mathrm{SD}$.

\begin{tabular}{llll}
\hline & Coarse & Medium & Fine \\
\hline $\mathrm{NO}_{2}{ }^{-}+\mathrm{NO}_{3}{ }^{-}$ & $0.1 \pm 0.1$ & $<0.1 \pm<0.1$ & $<0.1 \pm<0.1$ \\
$\mathrm{NH}_{4}{ }^{+}$ & $0.7 \pm 0.5$ & $0.3 \pm 0.1$ & $0.6 \pm 0.3$ \\
$\mathrm{PO}_{4}{ }^{3-}$ & $0.2 \pm 0.1$ & $0.1 \pm<0.1$ & $0.2 \pm 0.1$ \\
$\mathrm{Si}$ & $7.3 \pm 2.2$ & $8.4 \pm 1.3$ & $7.8 \pm 0.8$ \\
$\mathrm{O}_{2}$ & $8.7 \pm 0.5$ & $8.8 \pm 0.5$ & $9.0 \pm 0.7$ \\
\hline
\end{tabular}


Appendix 9. Porewater nutrient concentrations $\left(\mu \mathrm{mol} \mathrm{l}^{-1}\right)$ in the sediment types, mean $\pm \mathrm{SD}$.

\begin{tabular}{lllll}
\hline & $\begin{array}{l}\text { Sediment } \\
\text { depth } \\
(\mathrm{cm})\end{array}$ & Coarse & Medium & Fine \\
\hline $\mathrm{NO}_{2}{ }^{-}+\mathrm{NO}_{3}{ }^{-}$ & 1 & $3.1 \pm 1.8$ & $1.4 \pm 0.4$ & $2.6 \pm 0.9$ \\
& 3 & $5.5 \pm 2.1$ & $4.1 \pm 0.7$ & $3.9 \pm 2.2$ \\
& 5 & $5.2 \pm 2.7$ & $4.3 \pm 1.5$ & $5.8 \pm 4.6$ \\
& 10 & $6.4 \pm 2.6$ & $5.2 \pm 3.7$ & $7.4 \pm 6.1$ \\
$\mathrm{NH}_{4}{ }^{+}$ & 1 & $29 \pm 27$ & $39 \pm 33$ & $22 \pm 24$ \\
& 3 & $41 \pm 38$ & $64 \pm 38$ & $62 \pm 55$ \\
& 5 & $44 \pm 27$ & $48 \pm 27$ & $70 \pm 48$ \\
$\mathrm{PO}_{4}{ }^{3-}$ & 10 & $38 \pm 17$ & $49 \pm 38$ & $54 \pm 35$ \\
& 1 & $5.9 \pm 5.3$ & $12 \pm 5.0$ & $33 \pm 16$ \\
& 3 & $7.5 \pm 9.0$ & $16 \pm 15$ & $50 \pm 21$ \\
$\mathrm{Si}^{-}$ & 5 & $7.3 \pm 5.1$ & $10 \pm 7.0$ & $41 \pm 33$ \\
& 10 & $5.6 \pm 4.1$ & $12 \pm 14$ & $20 \pm 20$ \\
& 1 & $23 \pm 22$ & $38 \pm 32$ & $67 \pm 27$ \\
& 3 & $27 \pm 20$ & $58 \pm 40$ & $135 \pm 78$ \\
& 5 & $37 \pm 33$ & $59 \pm 31$ & $138 \pm 94$ \\
& 10 & $44 \pm 31$ & $60 \pm 20$ & $128 \pm 50$ \\
\hline
\end{tabular}

